\title{
Experimental Investigation of the Response of Precast Segmental Columns Subjected to Impact Loading
}

\author{
Xihong Zhang*, Hong Hao and Chao Li \\ Centre for Infrastructural Monitoring and Protection, Department of Civil and Mechanical \\ Engineering, Curtin University \\ Kent St., Bentley WA 6102, Australia \\ email: xihong.zhang@curtin.edu.au \\ Phone: +61 892669108
}

\begin{abstract}
Although precast concrete segmental columns have been more and more widely used in constructions, there is a lack of study on its behaviour under dynamic loading especially impact loading. In this paper, the fundamental behaviour of precast segmental columns under impact loading is investigated through laboratory tests. Scaled precast segmental columns with unbonded posttensioning tendon were constructed and tested by using pendulum impact system. Two segmental columns of the same height but with different numbers of precast segments were designed and tested. A conventional monolithic reinforced concrete ( $\mathrm{RC}$ ) column was also casted and tested as a reference column to compare the performance with segmental columns under impact loading. The impact load time history and column displacement time histories at column top, mid-height and column base were recorded. The deformation-to-failure processes of the columns were monitored by a high-speed camera, and used to investigate the response of different columns under impact loads. The test results showed the segmental column is more flexible than monolithic column, which leads to lower peak impact force but longer duration compared to those on the monolithic RC column. It was also found that comparing with monolithic column segmental column shows better performance against impact load with better self-centring capability, similar energy dissipation capability and less residual displacement and concrete damage.
\end{abstract}


Keywords: Precast concrete, segmental column, posttension, impact loading

\section{Introduction}

Recently much interest and attention have been directed to prefabricated structures, especially precast segmental structural members. This is mainly because precast structural elements can greatly reduce on-site construction time and cost, minimize traffic disruption due to construction work, improve work zone safety, reduce environmental impact, and improve construction quality. Time efficiency that can be achieved through utilizing precast segmental element is enormous. A study sponsored by the US Texas Department of Transportation (TxDOT) and the Federal Highway Administration (FHWA) concluded that using precast segmental element could reduce up to 50\% construction time [1] (Figure 1a). Apart from the above advantages, new materials such as ultra-high performance concrete and fiber reinforced concrete, etc., which sometimes require heated curing and/or careful mixing, can be easily applied in prefabrication factory to precast segmental elements.

Segmental columns have been popularly used in construction ever since ancient times. Many iconic structures around the world today were built hundreds or even thousands of years ago with segmental stone pillars, such as Brandenburg Gate, Germany built in 17881791 (Figure 1b), Tempo in Rhodes island, Greece built around $7^{\text {th }}$ Century B.C. (Figure 1c). One of the earliest modern constructions that utilized precast segmental concrete elements was Lavaca Bay Causeway, Texas, US in 1961 [1]. The application of precast segmental columns has gained its popularity globally ever since. Numerous modern constructions have successfully used precast segmental concrete columns. Examples of buildings and bridge structures that employed segmental concrete columns can be found in reference $[2,3]$. Despite all the above advantages, a major setback for precast segmental structures is that there is a lack of knowledge on its behaviour and performance under dynamic loadings, i.e. seismic loading, impact loading and blast loading. 
So far most existing studies on segmental columns under dynamic loadings have focused on the evaluation and improvement of its seismic performance. Very limited studies are reported on the behaviour of segmental columns under impact and blast loading. Many studies have reported the response and failure mode of segmental columns under seismic loading. For instance, Ou et al. [5] carried out numerical and analytical studies. It was found that under cyclic loading segmental column exhibited flag-shape behaviour, and it could undergo larger drift than monolithic column. Shim et al. [6] performed laboratory test on scaled segmental columns. It was observed that the tested columns all exhibited flexural failure in the plastic hinge region near column base. Shear failure such as shear slip at segmental joints or concrete shear failure within segments was not found [7]. Under earthquake excitation the primary response modes of segmental column are mainly flexural. Friction force at the column joints is generally sufficient to transfer shear force. However, this observation may not be true for a segmental column under impact loading, where shear deformation may govern the response and damage of the column.

The influences of various column specifications, such as the number of segment/joint, prestress level, etc. have also been investigated in previous seismic analysis of segmental columns. For instance, ElGawady and Dawood $[8,9]$ performed experimental and numerical studies on unbonded circular segmental columns. It was found that before joint opened, large segment and small segment had the same shear stresses at a given drift angle; after joint opened, the smaller segment had higher shear stress. Shim et al. [6] also conducted scaled cyclic tests on a series of segmental columns. It was concluded that the number of segmental joints had no effect on the ductile behavior if the location of the segmental joint was far from the plastic hinge region. Therefore, it was recommended by Shim et al. that focus should be paid to the base connection between the segment and the footing in seismic analysis. For the effect of prestress level, Wang et al. [10] found that under seismic loading prestress tendon helped to reduce column residual displacement. Nikbakht et al. [11] 
derived analytical solution and concluded that increasing prestress level would lead to higher column stiffness, increased column strength and improved energy dissipation capability. The influences of these factors on the performance of segmental column under impact loading are not known.

As emphasized above, despite many studies on segmental column response under seismic loading, research on impact resistance of segmental column is rare. The only article available in the literature is a recent numerical study on segmental column under vehicle impact [12]. A precast segmental column of $2.3 \mathrm{~m}$ in diameter and $16.25 \mathrm{~m}$ in height together with a detailed truck was modelled in the analysis. Under the impact from the truck at $60 \mathrm{~km} / \mathrm{h}$ impact velocity, a slight lateral slip was observed at the base joint between the first segment and the foundation. Therefore under lateral impact, shear resistance of the segmental column could be a major issue. Comparison was made to the responses between segmental column and cast-in-place monolithic column. A similar trend of concrete stress was found on the segmental column and the monolithic column. Due to the relatively lower stiffness, the response period of the segmental column was longer. Because of the large size of the columns modelled, no apparent column damage or failure was observed in the study. The failure of segmental column under impact load is therefore not investigated in that paper. Till now, no experimental study or analytical solution of segmental column subjected to impact loading can be found in the literature.

A few studies on the impact resistance performance of monolithic reinforced concrete column have been previously carried out, which might provide some reference to the possible response of segmental columns. Sha and Hao [13] performed experimental study on monolithic RC pier under barge impact. Pendulum impact system was utilized in the tests. Flexural failure was observed on the monolithic column at column mid-span where it was impacted and also at column base. Numerical model of monolithic column under impact 
loading was also built and validated with laboratory test results. Parametric study was carried out to investigate the influence of column parameters such as column height, diameter, and concrete strength, etc. on its responses. Some case studies on vehicle crash resistance of monolithic RC column and steel column were previously reported. For example, Buth and his co-workers $[14,15]$ performed experimental studies to evaluate the collision loads on bridge piers. Silva et al. [16] also carried out experimental study to investigate the impact resistance of RC column. El-Tawil et al. [17] evaluated the accuracy of AASHTO-LRFD vehicle collision provision on $\mathrm{RC}$ column under vehicle impact through numerical analysis. All these studies could help to predict the behaviour of segmental column under later impact loading. However, since the response and failure mode of a segmental column could be very different from that of a monolithic column, a proper study on segmental column under impact loading is needed.

In this study, laboratory test was performed to investigate the response of segmental column under impact loads using pendulum impact system. Two $800 \mathrm{~mm}$ tall $100 \mathrm{~mm}$ by $100 \mathrm{~mm}$ squared segmental columns were casted. One column was designed with 5 segments and the other with 7 segments. A steel impacter weighting $300 \mathrm{~kg}$ was lifted to designated heights and then released to generate the impact loading on the mid-height of the columns. A monolithic reinforced concrete column of the same height and cross-section area was also tested as reference for evaluating the performance of segmental columns. High-speed images of column deformation-to-failure process were recorded and used to analyse column response. The impact load time history and column deformation were recorded and analysed to evaluate the column performance.

\section{Test Setup}

To investigate the behaviour of segmental column under impact loading, three types of scaled columns including two segmental columns and one monolithic reinforced concrete 
column were designed and built in the laboratory. Pendulum impact system was utilized to generate the impact loading onto the column. Details of the test specimens and the setup of the pendulum impact system are descripted in the following.

\subsection{Test specimens}

Figure 2 shows the schematic view of the three specimens. The columns were $800 \mathrm{~mm}$ in height and had squared cross-sections of $100 \mathrm{~mm} \times 100 \mathrm{~mm}$ in dimension. The designated dimension of the tested columns represented quarter-scale model of a $3.2 \mathrm{~m}$ tall residential column. The height of the tested columns was restricted by the dimension of the pendulum impact testing system for the current experiment. Previous studies by Woodson and Baylot $[18,19]$ have demonstrated the suitability of quarter-scale model for RC column with similar dimensions subjected to blast loading. Column damage and response including load and deflection were well measured in their tests. It is therefore believed the current adopted scaled model could be able to properly represent the behaviour of segmental column under impact loading. A footing of $140 \mathrm{~mm}$ deep and $400 \mathrm{~mm} \times 400 \mathrm{~mm}$ cross-sectional area was built for each column to bolt them onto the strong floor. The monolithic column was cast with a $400 \mathrm{~mm} \times 400 \mathrm{~mm} \times 50 \mathrm{~mm}$ flanges at its top to support the added mass. A concrete block of $400 \mathrm{~mm} \times 400 \mathrm{~mm} \times 450 \mathrm{~mm}(\mathrm{~L} \times \mathrm{W} \times \mathrm{H})$ in dimension together with 5 pieces of $23 \mathrm{~kg}$ steel plates was placed on top of the columns, which gave a total weight of about $288 \mathrm{~kg}$ on top of the column. The weight of the column itself is about $18 \mathrm{~kg}$. The ratio of the supported weight to the column self-weight was therefore about 16 . Due to the restrain of the testing

149 system, there was no space for additional mass to be placed on top of the columns. Also,

150 because of the nature of impact test, inertia force from the added mass cannot be replaced 151 by directly applying axial force. No axial force was applied in addition to the added mass. The 152 barrels and wedges on both ends of the prestress tendons were anchored inside the footing 153 and on top of the steel plates. 
Figure 3 depicts the details of the test specimens. For the monolithic column, $6 \mathrm{~mm}$ diameter longitudinal rebar was extended into the top flange and the bottom footing, which created fully fixed boundary conditions for the monolithic column on both ends. The segmental columns were connected to the footing using two $6 \mathrm{~mm}$ diameter starter bars in the direction of loading. No grout or epoxy was used to glue the base segment to the footing. The top segment was left in direct contact with the concrete block above it. No reinforcement or grout was used to connect the top segment and the concrete block. The segmental column S5N included five pieces of $160 \mathrm{~mm}$ tall reinforced concrete segments. Four $4 \mathrm{~mm}$ diameter ties at $40 \mathrm{~mm}$ spacing were used to confine the concrete in each segment. Column S7N comprised of seven segments of $115 \mathrm{~mm}$ in height. 3 ties were included in each segment. It is worth noting the previous studies on the seismic response of segmental columns normally adopted columns with 2 to 6 segments [5-8]. Since plastic hinge is normally formed near the column base, the number of segments has been found having insignificant influence on column seismic response. For segmental column under impact loading, number of segment in a column could influence the column performance, because the impact may excite column local mode. Since this is the first impact test on segmental columns, two types of columns with five and seven segments were prepared to investigate the possible influence of the number of segments on its impact resistance. The segment height to cross-section length ratio were $1.6(160 \mathrm{~mm} / 100 \mathrm{~mm})$ for $\mathrm{S} 5 \mathrm{~N}$ and 1.15 $(115 \mathrm{~mm} / 100 \mathrm{~mm})$ for $\mathrm{S} 7 \mathrm{~N}$, which were similar to previously tested 4-segment and 6-segment columns under cyclic loading. Since the columns were impacted at their centres, to avoid impacting at segmental joints, columns with odd number of segments were designed and tested. For the monolithic column, $4 \mathrm{~mm}$ diameter ties were placed at $50 \mathrm{~mm}$ equal spacing throughout the column. For all the columns, $6 \mathrm{~mm}$ diameter ribbed bars were used as longitudinal reinforcement. For the segmental columns, the longitudinal rebar did not continue between segments. Apart from the prestress tendon, there was no additional link 
between adjacent segments. So under impact loading, the prestress tendon would take the tensile force, and the joints of segmental columns were designed to open freely so as to dissipate induced impact energy. Table 1 summarizes the specifications of the test specimens. The monolithic column had a longitudinal reinforcement ratio of $1.14 \%$, while that of the segmental columns were slightly higher $(1.16 \%)$ because of the void in the centres of segments to allow for the prestress tendon. The bending and shear stiffness of the monolithic column were about $2.65 \times 10^{5} \mathrm{~N} \mathrm{~m}^{2}$ and $9.93 \times 10^{7} \mathrm{~N}$. And its bending and shear capacities were $2296 \mathrm{~N} \mathrm{~m}$ and $22787 \mathrm{~N}$ respectively.

For the segmental columns, a $15 \mathrm{~mm}$ diameter hole was left for the prestress tendon when casting the columns. Seven-wire strands of $9.3 \mathrm{~mm}$ diameter were utilized as prestress tendons. The properties of the tendon are listed in Table 2. A prestress load of $30 \mathrm{kN}$ was jacked to the tendon after the columns were installed. The applied prestress load was about $10 \%$ axial capacity of the column. It should be noted that there is no guideline yet on the level of prestress for segmental column. The applied prestress load resulted in about 400MPa stress in the tendon, which is much lower than material yield stress. This application ensured the tendon would not yield when the column deforms, and would provide sufficient restoring force to pull the column back to its original position.

\subsection{Fabrication and material properties}

For quality control of the scaled column specimens, much attention was paid to the fabrication of formworks (Figure 4). Careful alignment was ensured during the fabrication and pouring of concrete to minimize construction errors. It was also important to ensure the position of reinforcement and the concrete cover depth.

Grade 25 self-compacting concrete with super plaster was used for casting of concrete columns. The maximum aggregate size was $10 \mathrm{~mm}$. The average compressive strength ( $\left.\mathrm{fc}^{\prime}\right)$ of 
concrete from five quasi-static compression tests on $100 \mathrm{~mm}$ diameter by $200 \mathrm{~mm}$ height cylinders under standard curing condition was $34 \mathrm{MPa}$. The flexural tensile strength $\left(\mathrm{f}_{\mathrm{t}}\right)$ of concrete from three four-point bending tests on $600 \mathrm{~mm} \times 100 \mathrm{~mm} \times 100 \mathrm{~mm}(\mathrm{~L} \times \mathrm{D} \times \mathrm{W})$ specimens was $5 \mathrm{MPa}$. Table 2 summarizes the material properties of concrete, reinforcement and prestress tendon.

\subsection{Instrument setup and measurement system}

Pendulum impact system was utilized in the current test. The pendulum impact system consisted of a steel frame, a pendulum arm, an impactor, and an inclinometer. As shown in Figure 5 , the steel frame was fixed on the strong floor to support the entire test system. A $300 \mathrm{~kg}$ steel impactor was connected to the frame through a $2.8 \mathrm{~m}$ long pendulum arm. In each test, the impactor could be lifted to a desired height (quantified through the lifting angle) and then released to strike the mid-height of the column. After the impactor hit the column and rebounded, the impactor was pulled back immediately to avoid a second impact on the column.

Figure 6 illustrates the measurement system. To measure the applied impact load a $25 \mathrm{t}$ load cell was fixed in front of the impactor. The load cell was calibrated on Baldwin universal testing machine. Three laser Linear Voltage Displacement Transducers (LVDT made by Keyence) were placed at column mid-height, column top and near column base behind the test specimens. The LVDT has a measuring range -of $150 \mathrm{~mm}$ each direction. The sensors were wired to a NI USB-9237 acquisition system and the data were captured at a sampling frequency of $50 \mathrm{kHz}$. A high-speed camera (Photron SA-Z) was installed to monitor the deformation-to-failure process of the columns. The filming rate of the high-speed camera was set to $8000 \mathrm{fps}$. The exposure time was set to balance with the aperture. Four halogen lights were used to provide intensive light for high-speed filming. Five tracking dots were glued to the middle of each segment for the segmental column S5N on its side. Another 
group of five dots were glued to the same heights on the monolithic column. And similarly seven tracking dots were used for column S7N. The high-speed camera images were postprocessed using digital image correlation software to derive the column displacement time histories at these tracking dots. For easy interpreting the test results, the segments and joints are numbered as Segment 01-07 and Joint 01-08 respectively (as depicted in Figure 3).

\section{Test Results}

The columns were tested with multiple impacts with progressively increasing the impact speed. The release angles of impactors started from 2.5 degree (Impact 01) which corresponded to an impact velocity of about $0.23 \mathrm{~m} / \mathrm{s}$. Then, the release angles were increased to 7 degree (Impact 02), 15 degree (Impact 03), and 30 degree (Impact 04), which corresponded to impact velocities of $0.64 \mathrm{~m} / \mathrm{s}, 1.37 \mathrm{~m} / \mathrm{s}$ and $2.71 \mathrm{~m} / \mathrm{s}$, respectively. After the above four impacts, if the column was still standing and holding the added mass, a final impact with release angle of 40 degree (Impact 05 ) and impact velocity of $3.58 \mathrm{~m} / \mathrm{s}$ was carried out which resulted in a thorough failure of the column. The initiative of the designed impact velocity was to assess the elastic response, minor damage, medium damage and ultimate failure of the columns under impact loading. Detailed observations on the test columns including high-speed camera images, column damage and failure modes are shown below. Quantitative results such as impact load time history, column displacement time history and displacement contours were also presented in the following section.

\subsection{Qualitative results}

\subsubsection{Deformation-to-failure process}

The response of each column under the strike of the impactor was monitored by a highspeed camera. Figure 8 and Figure 9 show the deformation-to-failure processes of the columns under progressively increased impact loading. Since the impact loads were relatively small in Impact 01 and 02 none of the columns experienced any significant 
deformation, the high-speed camera image sequences for Impact 01 and 02 are therefore not presented here. However, using digital image correlation the high-speed camera images were post-processed to derive the lateral displacement histories at the tracking dots. Then, the lateral displacement contours of these columns were mapped and presented for better illustration of the responses of the columns (Figure 7 and Figure 10).

As shown in Figure 7, in Impact 01 and 02 when the impact forces were relatively small the monolithic column deformation shape followed the local element mode with the large displacement initially occurred at the impacted location. This is because of the large inertial resistance generated by the lumped mass at the top of the column specimen upon impact, which prevented large movement of the column top although it was not restrained. The deflection shape, however, quickly changed to the fundamental mode of the column, especially in the free-vibration phase (the impact loading duration is about 0.02 to $0.03 \mathrm{sec}$ as shown in Figure 12) with the largest displacement at the column top. This is expected as the column requires least energy to vibrate with its fundamental mode. It could be observed that only positive deflections were developed on the monolithic column. In Impact 01, because the impact velocity was quite small, less noticeable inertia resistance was developed at the lumped mass on column top as compared to that in Impact 02. After Impact 02, concrete cracks were observed in the rear surface of the central part of the monolithic column indicating flexural tensile failure in the concrete. A diagonal shear crack was also found near the column base (Figure 11b). As shown in Figure 8a, when the monolithic column was impacted by the impactor released at 15 degree in Impact 03, the existing cracks around the mid-height of the column extended and opened further under the action of the lateral impact $(\mathrm{t}=5 \mathrm{~ms})$. The column showed an apparent large central deflection ( $t=26 \mathrm{~ms}$ ) indicating flexural deformation. A peak deflection of $14.6 \mathrm{~mm}$ was measured at the centre of the column. The shear crack near the column base was also widened under the impact loading (Figure 11a). Catastrophic column failure was resulted in 
Impact 04. As shown in Figure 9a, upon the impactor struck onto the column the existing cracks around the mid-span opened and began to extend at $\mathrm{t}=0.4 \mathrm{~ms}$. As the impactor forced the damaged column to further deform laterally, flexural cracks grew into major cracks and quickly extended across the central part of the column, and concrete crush occurred on the other side of the column ( $\mathrm{t}=4 \mathrm{~ms}$ ). The significant lateral impact loading also widened the existing shear crack near the column base. A complete concrete shear failure occurred at $t=7 m s$, and the shear force was merely resisted by the reinforcement. A total column collapse was observed at $t=57 \mathrm{~ms}$ with a flexural bending failure at the centre and base of the column and also a thorough diagonal shear failure near the base of the column.

The segmental column responded very differently to the impact loading. As depicted in the contour in Figure 7a, under the low level impact force in Impact 01, upon the impact the centre of the segmental column S5N deformed faster than column top and bottom. A peak deflection of $3.9 \mathrm{~mm}$ was reached at the centre of the column at $\mathrm{t}=20 \mathrm{~ms}$. This is because of the inertia resistance from the added mass on column top, which restrained the lateral displacement of the column top. After reaching the first peak deflection at column centre, the central part of the column rebounded under the action of the prestress tendon. In the meanwhile, the top part of the column continued to deform sideways with its lateral displacement exceeded that in the centre of the column. The entire column vibrated freely around its original position until it came to a rest. Similar response was observed for column S5N in Impact 02. No apparent damage was found on this segmental column after Impact 02. When the impactor was released at 15 degree, damage to the segmental column appeared. As shown in Figure $8 \mathrm{~b}$, at $\mathrm{t}=5 \mathrm{~ms}$, as the flexural induced compressive stress in the concrete exceeded its compressive strength, concrete crack was formed on the top left corner of Segment 03. As the impactor forced the column to further deform and bend, the concrete crack extended. At $t=45 \mathrm{~ms}$, the top left corner of the segment failed due to compression. An apparent joint opening was found between the Segment 03 and 04 . The joint opening 
developed wider as column S5N continued to deform and bend. But the size of opening gradually reduced and then closed as the deformation shape transformed from a mid-span deformation governed flexural bending to top deformation led free-vibration (shown in Figure $8 b)$. The entire column vibrated freely around its base. A maximum displacement of around $53 \mathrm{~mm}$ was measured at the top of the column. The large bending force transferred through the column and starter bars to the footing, which resulted in minor damage to the footing ( $t=252 \mathrm{~ms})$. Nevertheless, the segmental column $\mathrm{S} 5 \mathrm{~N}$ eventually restored to its original position with a small residual displacement $\left(\delta_{\text {resi }}=3.8 \mathrm{~mm}\right)$ at column top. In Impact 04, larger joint opening was found as a result of more significant flexural bending under the increased impact loading. Concrete in the compressive surface of this joint was further crushed because of the flexural compression and also the direct impact force on the segment. In the meanwhile, because of the excessive flexural bending the base segment (Segment 01) was bent and rotated with its right bottom corner crushed against the footing ( $t=78 \mathrm{~ms}$ in Figure $9 \mathrm{~b})$. Owing to the rotation of the bottom segment, the starter bar pulled the footing, which resulted in some tensile damage to the concrete footing. Nevertheless, the segmental column still supported the added mass on its top. Because the footing was damaged no further test was carried out.

The response of column S7N was very similar to column S5N especially in Impact 01 and 02 when the levels of impact load were low. When the impact load was increased with the impactor released at 15 degree, concrete compressive failure was also observed. But as shown in Figure $8 \mathrm{c}$, the segmental column bent in the centre at $\mathrm{t}=13 \mathrm{~ms}$ as the impact excited the local mode of the column. As the column continued to deform, the curvature began to shift upwards, and the local mode gradually transferred into global mode with the largest curvature shifted from column centre towards column top. At $\mathrm{t}=37 \mathrm{~ms}$, with excessive lateral deformation compressive stress in the concrete at the Segment 05 and 06 reached failure stress. Concrete was crushed in the compressive face of the two segments. With the 
further increased impact load by releasing the impactor at 30 degree (Figure 9c), the centre of the column was forced by the impactor to bend significantly. More severe concrete crushing failure occurred on Segment 04 and 05 at $t=120 \mathrm{~ms}$ because of the large flexural induced compressive failure and also the large impact force from the impactor directly. Some compressive damage on the base segment (Segment 01) was also found as the column rotated against its base. An opening could be observed in the base joint (Joint 01) as the column experienced large flexural bending. Despite the damage to concrete in some segments, after free vibration column S7N still managed to survive the impact with obvious residual deformation. A final impact (Impact 05) was then carried out on column S7N to examine its ultimate impact resistance capability. Figure 9d shows the deformation-tofailure process of the column. As can be seen, Segment 04 in the middle of the column was badly smashed by the impactor. As the column bent, Segment 05 was seriously crushed due to the extreme flexural bending. The base segment was also severely damaged in its compressive surface as it rotated around the footing (Figure 11). Plastic deformation was formed in the starter bar, and after Impact 05 column S7N was left with large residual deformation. Because the compressive damage extended to the neutral axis in Segment 05, the segments and the added mass above Joint 05 lost its stability and the column was considered failed completely.

\subsubsection{Failure mode}

The failure of the monolithic column was governed by flexural failure and shear failure. As the level of impact load increased, flexural tensile damage to concrete in the rear face of the monolithic column was observed in Impact 02 (Figure 11b), which grew into major critical cracks (Figure 11a). The tensile cracks led to the flexural failure of the column (Figure 11d) when the impact load was further increased. Diagonal shear failure near column base was also found in the monolithic column which also initiated in Impact 02 (Figure 11b). As 
the impact loading was increased, the shear crack further developed leading to complete failure of the column.

The damage and failure pattern of the segmental columns differed from those of the monolithic column. Under the lateral impact loads, the columns also exhibited flexural deformation. Instead of resulting in concrete tensile cracks, segmental joints opened in responding to larger curvature in the column. When the column was subjected to larger impact loading, compressive damage to concrete in the compressive side of the joint would be expected (Figure 11c). When the segmental columns were subjected to large flexural deformation, the base segment rotated at the footing. Compressive damage to base segments occurred when the compressive stress exceeded the concrete strength (Figure 11d and c). Also, the footing around column base would be subjected to larger flexural actions. If no starter bars were used, the prestress tendon would take the tensile force and the concrete segment take the compressive force. When starter bars were used to connect the base segment and the footing, which was quite commonly adopted in seismic design so as to improve energy dissipation capability, the force transferred to the footing would increase. Damage to footing was therefore more likely to occur (Figure 11d).

\subsection{Quantitative results}

The impact load time history, displacement time histories at column top, centre and base were recorded during the tests. Because the restrain of footing, the displacement at column base was generally quite small except for the monolithic column with shear failure. Therefore, the displacement at column base is not given here. The test results including the peak impact force, maximum column central displacement and residual displacement, and the maximum and residual displacement at column top are summarized in Table 3 and 4.

\subsubsection{Impact load time history}



performance. Figure 12 shows the load time history measured on the columns. As shown in Figure 12a, in Impact 01 upon the impactor stuck on the monolithic column the load increased sharply to about $12 \mathrm{kN}$ then attenuated gradually to zero. The sharp rise in the impact load was because of the rigid impactor itself, the stiffness and inertia resistance of the column. As the release angle was increased to 7.5 degree and 15 degree, the peak impact load rose to about $22 \mathrm{kN}$ and $38 \mathrm{kN}$, respectively. The loading duration also became slightly longer ( $30 \mathrm{~ms}$ and $45 \mathrm{~ms}$ ). In Impact 04 , the peak impact load reduced to about $29 \mathrm{kN}$ because the monolithic column was severely damaged in the previous impacts and lost much of its stiffness. The shape of the impact load on the monolithic column was primarily triangle shape which differed from the five-point impact loading diagram to model the 392 vehicle impact loading [12]. This is because the impactor in the current pendulum impact system was made of solid steel blocks, which was much more rigid than that of the vehicle in the reference. The latter will deform significantly as the vehicle impacts on the column which leads to a more gradual rising phase of the load.

The impact load time histories recorded on the segmental columns were different from those on the monolithic column. Figure $12 \mathrm{~b}$ shows the load time histories for the segmental column S5N. As shown, upon Impact 01 the load quickly increased to about $7 \mathrm{kN}$ when the impactor stuck on the column. The load reduced gradually after the peak force to about $2.5 \mathrm{kN}$. Then it increased to about $7 \mathrm{kN}$ resulting in a second peak load. The two-peak impact load time history on the segmental column differed from that on monolithic column which had only single peak. There are two possible reasons: firstly, this is because of the interaction between the impactor and the segmental column. As shown in Figure 13b, the LVDT behind the centre of the column monitored that the central segment quickly reached a peak displacement under the impact force. It then rebounded quickly back. This response of 
time history. Secondly, the second peak could be resulted from the prestress tendon. The $9.3 \mathrm{~mm}$ diameter tendon was placed in the $15 \mathrm{~mm}$ hole of the segments. There was in

409 general a gap of 2-3mm between the segment and the prestress tendon. When the impactor struck on the column, only the concrete segments provided resistance. But as the impactor forced the segments to deflect and hit the post-tensioned tendon, the tendon also provided resistance to the impactor. Hence another peak on load time history was formed. In future test, the force in the tendon shall be monitored to validate this explanation. As the impactor were released at larger angles, i.e. 7.5 degree and 15 degree in Impact 02 and 03, the peak loads increased to about $13.5 \mathrm{kN}$ and $21 \mathrm{kN}$. Because the central segment was damaged in Impact 03 and 04 , the interaction between the load cell and the column became more complex as evidenced on the tracked load time histories which were associated with more fluctuations. Since the column was damaged with degraded stiffness, the peak impact load measured on Impact 04 was merely above $22 \mathrm{kN}$ but with longer duration (about $180 \mathrm{~ms}$ ). Similar load time histories were recorded on column S7N. In Impact 03, since segment damage was only found on Segment 05 and 06 whereas the central segment (Segment 04) was still intact, no load fluctuation was observed during its attenuation phase. Instead, fluctuation was found on load time history in Impact 04 and 05 when the central segment experienced significant damage. As the column suffered severe damage in Impact 04, the peak load measured in Impact 05 reduced to about $20 \mathrm{kN}$ whereas a peak of about $24 \mathrm{kN}$ was measured in Impact 04.

The recorded load time histories were integrated with time to derive the corresponding impulses. Together with the peak impact forces, the derived impulses are provided in Table 3. The measured impact load time histories for the three tested columns at each impact velocities showed consistency. It is therefore believed that the measured load time history is reliable. The impact velocity was estimated from the releasing height of the impactor as well as the high-speed camera images. It is to note that for conservation of momentum the 
impulse is related to not only the initial velocity and rebound velocity of the impactor but also the momentum, deformation and damage of the column. Since the impact energy would impart into the column and consumed by converting to the column kinetic energy, elastic and plastic energy, and by friction between segments and segments opening and closing, etc., it would not be accurate enough to only assess impactor initial and rebound velocities to check the consistency of impulse.

\subsubsection{Central and top displacement time histories}

The lateral displacements were measured by the LVDT, which were carefully validated with the measurements of high-speed camera images before being analysed. The column central and top displacement time histories are plotted in Figure 13. For the monolithic column, peak central deflections of about $5.2 \mathrm{~mm}$ and $7.5 \mathrm{~mm}$ were resulted in Impact 01 and 02 , respectively. In Impact 03, a peak central deflection of about $14.6 \mathrm{~mm}$ was measured. In Impact 04, because the monolithic column failed directly under the significant impact force, the recorded central deflection increased sharply to over $200 \mathrm{~mm}$ (Figure 13a). The central deflections of the segmental columns were very different from that of monolithic column. In general, the maximum deflections at column centres were found during the forced vibration phase. The columns rebounded and then further deflected to reach a second peak deflection. The measured peak central deflections increased under larger impact load. For the segmental column S5N, in Impact 01 a peak deflection of $3.9 \mathrm{~mm}$ was measured, while the peak deflections increased to $7.7 \mathrm{~mm}$ and $32.8 \mathrm{~mm}$ when the impactor was released at 7.5 degree and 15 degree in Impact 02 and 03 , respectively. In Impact 04 , the peak deflection rose to about $108.4 \mathrm{~mm}$ despite the measured impact load did not increase substantially. This larger deflection recorded was mainly because of the degraded column stiffness in the previous impacts and also the longer loading duration in this impact. The peak central deflections measured on the segmental column S7N were slightly larger than those in column $\mathrm{S} 5 \mathrm{~N}$. A maximum central displacement of $5.1 \mathrm{~mm}$ and 
$11.5 \mathrm{~mm}$ were found for column $\mathrm{S7N}$ in Impact 01 and 02 . This was mainly because the segmental column S7N with more segments was relatively more flexible than column S5N. In the following impact, peak deflections of about $24 \mathrm{~mm}$ and $104 \mathrm{~mm}$ were measured on column S7N in Impact 03 and 04.

The lateral displacement at column top strongly influences the performance of the column. Because of P-delta effect, large lateral displacement at column top would introduce large moment to the column and increase the potential of column overturn and collapse. Figure $13 \mathrm{~b}$ shows the recorded displacement time histories at column top. For the monolithic column, the peak displacements at column top were in general larger than that at the centre of the column. For instance, in Impact 01 and 02 the column top displacements of $6.6 \mathrm{~mm}$ and $11.7 \mathrm{~mm}$ were recorded, whereas those at column centre were $5.2 \mathrm{~mm}$ and $7.5 \mathrm{~mm}$. For the segmental columns, peak column top displacements occurred during free vibration phase after the impact, and the values were normally larger than those at column centres. For example, in Impact 01 when the impact load was small a maximum column top displacement of about $6.1 \mathrm{~mm}$ were found on $\mathrm{S} 5 \mathrm{~N}$, while the maximum displacement at column centre was $3.9 \mathrm{~mm}$. In Impact 04 when the impact load was large, a maximum top displacement of $116 \mathrm{~mm}$ was recorded while the maximum displacement at column centre was about $108 \mathrm{~mm}$.

\subsubsection{Residual displacement}

Residual displacement of columns after the impacts was another concern. The residual displacements on the tested columns at each impact velocity were measured by LVDT. Considering the large amount of data, some of the displacement time histories were abridged so as to concentrate on comparing column forced response. As shown in Figure 13, after the impact loading the monolithic column vibrated freely but because of plastic deformation of reinforcement and concrete damage, the monolithic column would not 
restore its original position. A residual displacement of about $1.5 \mathrm{~mm}$ was recorded at the column centre after Impact 01. Increased permanent deformation was accumulated in the impacts with residual displacements of $3.0 \mathrm{~mm}$ and $11 \mathrm{~mm}$ at column centre after Impact 02 and 03 . In comparison, the segmental columns exhibited much better self-centring capability. Under the low level impact forces, the segmental columns deformed and then vibrated freely. They were always capable of coming to their original positions with very small residual displacements. For example, after Impact 01 and 02 the residual displacements at the centre of column $\mathrm{S} 5 \mathrm{~N}$ were merely $0.5 \mathrm{~mm}$ and $1 \mathrm{~mm}$ respectively. Those for column $\mathrm{S} 7 \mathrm{~N}$ with more segments were slightly larger $(0.7 \mathrm{~mm}$ for Impact 01 and $1.6 \mathrm{~mm}$ for Impact 02). Even under large level impact loads when damage occurred to concrete, a significant less residual displacement was observed by the segmental columns. For instance, after Impact 03 the residual central displacement of column $\mathrm{S} 5 \mathrm{~N}$ was $3.6 \mathrm{~mm}$ and that for column S7N was only $2.6 \mathrm{~mm}$. After Impact 04 in which concrete segments experienced partial compressive damage, the residual displacement at the centre of column S7N was slightly over $7 \mathrm{~mm}$. Therefore, it can be found comparing with conventional monolithic column segmental column shows much better self-centring capacity when subjected to lateral impact loading. The better self-centring feature of segmental column was primarily because of the following two reasons: firstly, when the segmental column deformed sideway, the horizontal component of the large prestress force in the tendon would pull the swayed column back to its original position. Secondly, since the longitudinal reinforcements in the segments do not extend through the entire column, the flexural deformation of the column under lateral loading mainly led to the opening and closure of segmental joints. No plastic deformation was developed in the reinforcements. The flexural tension within the cross section of the segmental column was undertaken by the prestress tendon. With much higher yield strength of material and proper designed tendon diameter, much less or even no plastic deformation could be developed in the prestress tendon. 


\section{Analysis and discussion}

511 In this section, the performance of segmental column under lateral impact loading is

512 analysed. Comparison is made between segmental column and conventional monolithic

513 column. Analysis is made with regard to the impact load, lateral displacement at column

514 centre, and energy dissipation. The effect of the number of segments is also discussed.

\subsection{Impact load}

The impact load onto the column is an important factor when studying column impact resistance capability. As described in Section 3, despite the impactor was made of the same weight and was released at the same height each time, the measured impact loads varied between the two segmental columns and the monolithic column. This was mainly because the action of the impactor was coupled with the response of the target column. To better

521 analyse the impact load and the response of the segmental column, the measured load time 522 histories for the three different columns in each impact are summarized and plotted 523 together in Figure 14. As shown in Figure 14a for Impact 01, the load on the monolithic column increased more sharply as the impactor struck on the column, while because of the relatively low stiffness with segmental joints, the loads on the two segmental columns increased more gradually. A peak load of about $12 \mathrm{kN}$ was measured on the monolithic column while those for the segmental columns were around or below $8 \mathrm{kN}$. $38 \%$ and $31 \%$ lower peak loads were resulted on segmental columns $\mathrm{S} 5 \mathrm{~N}$ and $\mathrm{S} 7 \mathrm{~N}$ respectively. After reaching the peak load, the impact force on the monolithic column dropped quickly to zero.

530 The total loading duration on the monolithic column was only about $20 \mathrm{~ms}$. Because of the

531 deformation and rebound of the segmental column, the impact forces made second peaks

532 after they reduced from the first peak loads. It should be noted that from mechanical point 533 of view, a segmental column can be simplified as a series of bars jointed by non-linear 534 springs. Column S5N and S7N were of the same height and cross-section. And the moment- 
curvature relation for the joint spring would also be the same as the same level of prestress was used. Column S7N comprised of more joints than S5N. Under the same loading, more joints would open on $\mathrm{S} 7 \mathrm{~N}$ than $\mathrm{S} 5 \mathrm{~N}$, which results in larger deflection. Therefore, $\mathrm{S} 7 \mathrm{~N}$ is less stiff than S5N. As a result, the loading duration on S7N was slightly longer (approximately $52 \mathrm{~ms}$ ) than column S5N (about $42 \mathrm{~ms}$ ). Similar impulses were found on segmental column S5N (141kN ms) and monolithic column (134kN ms); while due to longer loading duration larger impulse was resulted on column S7N (about 203kN ms). Similar trend can be observed in Figure $14 \mathrm{~b}$ for Impact 02 . With the impactor released at 7 degree, the peak impact force on the monolithic column increased to about $22 \mathrm{kN}$, while those on the two segmental columns $\mathrm{S} 5 \mathrm{~N}$ and $\mathrm{S} 7 \mathrm{~N}$ were about $13 \mathrm{kNand} 12 \mathrm{kN}$ which were $38 \%$ and $45 \%$ less than that on the monolithic column. And the loading durations extended to about $30 \mathrm{~ms}$ for the monolithic column, which was still shorter than those on the two segmental columns $(50 \mathrm{~ms}$ for $\mathrm{S} 5 \mathrm{~N}$ and $66 \mathrm{~ms}$ for $\mathrm{S} 7 \mathrm{~N})$. The impulse on column $\mathrm{S} 5 \mathrm{~N}(300 \mathrm{kN} \mathrm{ms})$ was still approximately the same with monolithic column (290kN ms), while that on column S7N was about $10 \%$ (323kN ms) more than that on monolithic column. Despite the monolithic column suffered damage (concrete tensile cracks and diagonal shear crack) in the previous impact, the peak impact loading on this column in Impact 03 was still much higher than the two segmental columns. A peak load of about $38 \mathrm{kN}$ was recorded. Much lower peak forces were recorded on the two segmental columns. The peak load measured on column $\mathrm{S} 5 \mathrm{~N}$ was slightly larger (about $21 \mathrm{kN}$, but $45 \%$ less comparing with the monolithic column) than that on S7N (about $17 \mathrm{kN}$, and $57 \%$ less comparing with the monolithic column). This was because with more segmental joints, $\mathrm{S} 7 \mathrm{~N}$ is more flexible than $\mathrm{S} 5 \mathrm{~N}$. In the meanwhile, as the loading duration on the segmental columns was longer, $15 \%$ and $17 \%$ higher, impulses resulted on column S5N and S7N were larger than that on the monolithic column. Upon the impact, column S7N exhibited more joint openings. In Impact 04, the peak impact force on the monolithic column dropped to about $29 \mathrm{kN}$ as the column was previously damaged. The impactor forced 

the column to deform to failure and the loading duration was merely about $30 \mathrm{~ms}$. Despite both of the two segmental columns experienced minor concrete crushing damage in their segments, in face of the impactor striking with higher velocity they were still capable of resisting the impact. Larger peak impact forces were measured on these two columns than previously in Impact 03. As shown in Figure 14d, for column S5N the impactor forced the column to deform. After reaching a peak load of $22 \mathrm{kN}$, the force reduced quickly to almost zero because the concrete bearing the impacting force was crushed. As the impactor continued to push the column forward, the force increased and then dissipated gradually.

The recorded peak forces and the derived impulses are summarized and plotted in Figure 15. As shown, when the impactor of the same weight struck with the same impact velocity (same releasing angle), higher peak forces were always observed on the monolithic column than that on the segmental columns. But similar or even larger impulses were always found on the segmental columns because of longer impact duration. The peak forces on the segmental column with five segments were slightly higher than that on the one with seven segments. This is because the stiffness of column S5N was relatively higher than that of column S7N with more joints.

\subsection{Column response}

To evaluate column response under impact loading, the recorded central deflection time histories in each impact test are plotted and compared in Figure 16. Under the impact loading, the responses of the monolithic column were featured with a peak deflection and the column quickly rebounded with noticeable residual displacements. The behaviour of the segmental columns was very different. A peak central deflection was usually resulted during the forced vibration phase. The columns then rebounded but quickly vibrated back to make a second peak deflection. The segmental columns then vibrated freely about their original positions until they came to a rest, with much smaller residual deflections. In addition, the 
segmental column with more joints vibrated slower than the other one with less number of joints. For instance, in Impact 01 the free vibration period of column $55 \mathrm{~N}$ was about $0.4 \mathrm{~s}$, while that for column S7N was nearly $0.6 \mathrm{~s}$. It indicates column S5N is stiffer than S7N. It is worth noting that in Impact 01 and 02 , there was no apparent joint opening observed through the high-speed camera images as shown in Section 3. With the same column dimension, reinforcement ratio, prestress force, and boundary condition, the stiffness of the segmental columns with different number of joints still differs. The test results therefore show that even before any joint opening is formed, it is not appropriate to simplify the segmental column with Bernoulli-Euler beam theory when estimating its deflection.

When segmental joints opened, the period of the column became longer. As shown in Figure $16 \mathrm{c}$, when the joint of column $\mathrm{S} 5 \mathrm{~N}$ was forced to open in Impact 03 the vibration period stretched to $0.7 \mathrm{~s}$. But as column rebounded the opened joint was closed. It is evidenced that the deflection curve was not a smooth sinusoidal curve. With multiple joint openings on column S7N, the vibration period was even longer.

To evaluate the response of the segmental columns and compare their performance with monolithic column, the maximum column central deflections are summarized and plotted versus the impulse that each column experienced. As shown in Figure 17a, in general the maximum deflection increases with the applied impulse for both monolithic and segmental columns. When the impulse was low, a larger maximum deflection was found on the monolithic column than on the segmental columns. For instance, when the impulse was about $128 \mathrm{kN}$ ms, a maximum deflection of $5.2 \mathrm{~mm}$ was measured on the monolithic column while under a similar impulse, the maximum deflection of the segmental column S5N was $3.0 \mathrm{~mm}$ ( $42 \%$ less than the monolithic column). Although the impulse was much larger on column S7N (about 192kN ms), the measured maximum deflection was still smaller (5.1mm). This was mainly because the prestress prevented joint opening on the segmental columns 
611 when the impact load was relatively small, which minimized the column deflection. As the impulse increased, joint openings occurred. Larger maximum central deflections were then measured on segmental columns than those on the monolithic column. For example, a maximum central deflection of $14.6 \mathrm{~mm}$ was measured on the monolithic column when subjected to $478 \mathrm{kN}$ ms impulse. In comparison, the maximum deflections of $32.8 \mathrm{~mm}$ and $24.3 \mathrm{~mm}$ were recorded on column $\mathrm{S} 5 \mathrm{~N}$ and $\mathrm{S} 7 \mathrm{~N}$ with respect to about $560 \mathrm{kN}$ ms impulse. Under approximately the same impulse in Impact 03 and 04 the maximum deflections of column S5N were $26 \%$ larger than those of S7N. This was because the footing of column S5N was partially damaged which led to a more flexible base connection for this column in Impact 03 and 04.

The segmental columns show more advantages over monolithic column in terms of residual deflection. As shown in Figure 17b, for all the impacts in the current study smaller residual deflections were always measured on the segmental columns. For instance, under low level impulse (approx. $128 \mathrm{kN} \mathrm{ms}$ and $288 \mathrm{kN}$ ms for Impact 01 and 02 ), residual deflections of $1.5 \mathrm{~mm}$ and $2.9 \mathrm{~mm}$ were measured on the monolithic column. In comparison, less than $1 \mathrm{~mm}$ residual deflections (merely $1 / 3$ of that on monolithic column) were 627 measured on the segmental column S5N. As the impulse increased to about $480 \mathrm{kN}$ ms, the monolithic column experienced severe flexural and shear damage with a residual deflection of about $11 \mathrm{~mm}$. In contrast, under even larger impulse (about 560kN ms), a residual deflection of $3.6 \mathrm{~mm}$ was found on the segmental column $\mathrm{S} 5 \mathrm{~N}$, which was over $67 \%$ less than that on monolithic column. It can therefore be concluded that under lateral impact loading segmental column shows much better self-centring capacity than conventional monolithic column. This was because no plastic deformation was formed in its longitudinal reinforcement and the prestress tendon inside the segmental column pulled the swayed column back. It should be noted that the level of residual displacement should also depend on the prestress level, which will be investigated in future studies. Similar level of residual 

loading because there was no joint opening on either column. When column S5N was subjected to about $144 \mathrm{kN}$ ms and $288 \mathrm{kN}$ ms impulse, the residual deflections were about $0.5 \mathrm{~mm}$ and $1 \mathrm{~mm}$. Under about $208 \mathrm{kN} \mathrm{ms}$ and $320 \mathrm{kN}$ ms impulse, the residual deflections of column S7N were $0.7 \mathrm{~mm}$ and $1.6 \mathrm{~mm}$ (indicating $40 \%$ and $60 \%$ more than those of column S5N), respectively. Again, because the footing of column S5N was damaged in Impact 03, the footing could not provide the same restrain to the column. As a result, larger residual deflections (about $3.6 \mathrm{~mm}$ and $28.0 \mathrm{~mm}$ ) were measured on column $\mathrm{S} 5 \mathrm{~N}$ when subjected to $560 \mathrm{kN}$ ms and $912 \mathrm{kN}$ ms impacts. Under the similar magnitudes of impulses the residual deflections of column S7N were $2.6 \mathrm{~mm}$ and $7.3 \mathrm{~mm}$, respectively.

\subsection{Energy absorption}

Energy absorption is another important parameter in evaluating column impact resistance capability. The energy absorption depends on the load and deformation history rather than the permanent deformation. Figure 18 shows the impact load versus column central deflection for the three columns in each impact. The enclosed area by the load and deflection curve represents the energy dissipated through column deformation and damage. According to Figure 18, the impact loads on the monolithic column are in general higher than those on the segmental columns. But the deformations of the segmental columns are always larger. It is therefore not straightforward to directly assess the energy dissipation capabilities of the columns. The dissipated energy derived from the enclosed area of the 657 load-deflection curves are plotted against the impulses. As shown in Figure 19 when the applied impulses were relatively low, very similar levels of the energy were dissipated by the monolithic column and the segmental column. The monolithic column failed at the impact with an impulse of about $480 \mathrm{kN}$ ms, but the two segmental columns were still capable of resisting impact loads and dissipating more energy. The monolithic column dissipated the 
Damage accumulated with noticeable residual displacement even under small impact.

664 Segmental column was capable of dissipating the imposed impact energy through more

665 versatile forms. Upon impact, the column could deform substantially owing to joint opening, and then vibrated which transforms the impact energy to kinetic energy of the column. The deflection of the segmental column also led to the stretch of the prestress tendon. Localized plastic deformation was observed on the prestress tendon around the mid-height of the column. Therefore the plastic deformation of prestress tension would also dissipate energy. Other means such as concrete crushing damage, friction between segments at joints etc. would also dissipate impact energy.

\section{Summary}

In this paper, we performed pendulum impact tests to investigate the impact resistance capacity of segmental columns. The fundamental behaviour of precast segmental column with posttensioning tendon under impact force was studied. Comparison was made between segmental column and conventional monolithic column. The deformation-tofailure processes of the columns were monitored by a high-speed camera. The impact load and the lateral displacement time histories were measured and used to evaluate column performance. The testing results concluded that the segmental column is more flexible than conventional monolithic column. Under high level impact, segmental joints near and above the impacted segment would open. Column with more segmental joints is more flexible with multiple openings at the joints near the impact location. Because of the relatively lower stiffness of segmental columns, smaller peak impact forces but similar impact impulses were measured on these columns as compared with those on monolithic column when the impactor was striking at the same velocity. The segmental columns have better self-centring capacity with smaller residual displacements as compared to the monolithic column. With the same column dimension and reinforcement ratio, similar level of energy could be dissipated by the segmental column and the monolithic column; but the segmental column 
mechanism such as joint opening, friction and more column vibration.

\section{Acknowledgement}

The authors would like to acknowledge ARC for financially supporting this project. The first author would like to thank Mr James Water in the structure lab of the University of Western Australia for his assistance in conducting the test. The authors would also like to address $\mathrm{Mr}$ Matt Brockman in actively involving in this test for his final year project.

\section{Reference}

[1] M. Shahawy, Prefabricated Bridge Elements and Systems to limit traffic disruption during construction, Technical Report, Transportation Research Board, 2003.

[2] M.M. Sprinkel, Prefabricated bridge elements and systems, NCHRP Synthesis of Highway Practice, (1985).

[3] Y.-C. Ou, Precast segmental post-tensioned concrete bridge columns for seismic regions, PhD thesis, State University of New York at Buffalo, 2007.

[4] S. Billington, R. Barnes, J. Breen, Alternate substructure systems for standard highway bridges, Journal of Bridge Engineering, 6 (2001) 87-94.

[5] Y.-C. Ou, M. Chiewanichakorn, A.J. Aref, G.C. Lee, Seismic performance of segmental precast unbonded posttensioned concrete bridge columns, Journal of structural engineering, 133 (2007) 1636-1647.

[6] C.S. Shim, C.-H. Chung, H.H. Kim, Experimental evaluation of seismic performance of precast segmental bridge piers with a circular solid section, Engineering Structures, 30 (2008) 3782-3792.

[7] T.-H. Kim, H.-M. Lee, Y.-J. Kim, H. Shin, Performance assessment of precast concrete segmental bridge columns with a shear resistant connecting structure, Engineering Structures, 32 (2010) 1292-1303.

[8] M.A. ElGawady, H.M. Dawood, Analysis of segmental piers consisted of concrete filled FRP tubes, Engineering Structures, 38 (2012) 142-152.

[9] H. Dawood, M. ElGawady, J. Hewes, Behavior of segmental precast posttensioned bridge piers under lateral loads, Journal of Bridge Engineering, 17 (2011) 735-746.

[10] Z. Wang, J. Ge, H. Wei, Seismic performance of precast hollow bridge piers with different construction details, Frontiers of Structural and Civil Engineering, 8 (2014) 399-413. [11] E. Nikbakht, K. Rashid, F. Hejazi, S.A. Osman, Application of shape memory alloy bars in self-centring precast segmental columns as seismic resistance, Structure and Infrastructure Engineering, 11 (2015) 297-309.

[12] C.H. Chung, J. Lee, J.H. Gil, Structural performance evaluation of a precast prefabricated bridge column under vehicle impact loading, Structure and Infrastructure Engineering, 10 (2014) 777-791.

[13] Y. Sha, H. Hao, Laboratory tests and numerical simulations of barge impact on circular reinforced concrete piers, Engineering Structures, 46 (2013) 593-605.

[14] C.E. Buth, W.F. Williams, M.S. Brackin, D. Lord, S.R. Geedipally, A.Y. Abu-Odeh, Analysis of large truck collisions with bridge piers: phase 1. Report of guidelines for designing bridge piers and abutments for vehicle collisions, 2010. 
[15] C.E. Buth, M.S. Brackin, W.F. Williams, G.T. Fry, Collision Loads on Bridge Piers: Phase 2. Report of Guidelines for Designing Bridge Piers and Abutments for Vehicle Collisions, 2011. [16] P.F. Silva, W.D. Mesia, D. Marzougui, S.S. Badie, Performance evaluation of flexure impact resistance capacity of reinforced concrete members, ACI Structural Journal, 106 (2009).

[17] S. El-Tawil, E. Severino, P. Fonseca, Vehicle collision with bridge piers, Journal of Bridge Engineering, 10 (2005) 345-353.

[18] S.C. Woodson, J.T. Baylot, Structural collapse: quarter-scale model experiments, DTIC Document, available online, 1999.

740 [19] S.C. Woodson, J.T. Baylot, Quarter-scale building/column experiments, Adv. Technol. 741 Struct. Eng, (2000) 1-6. 


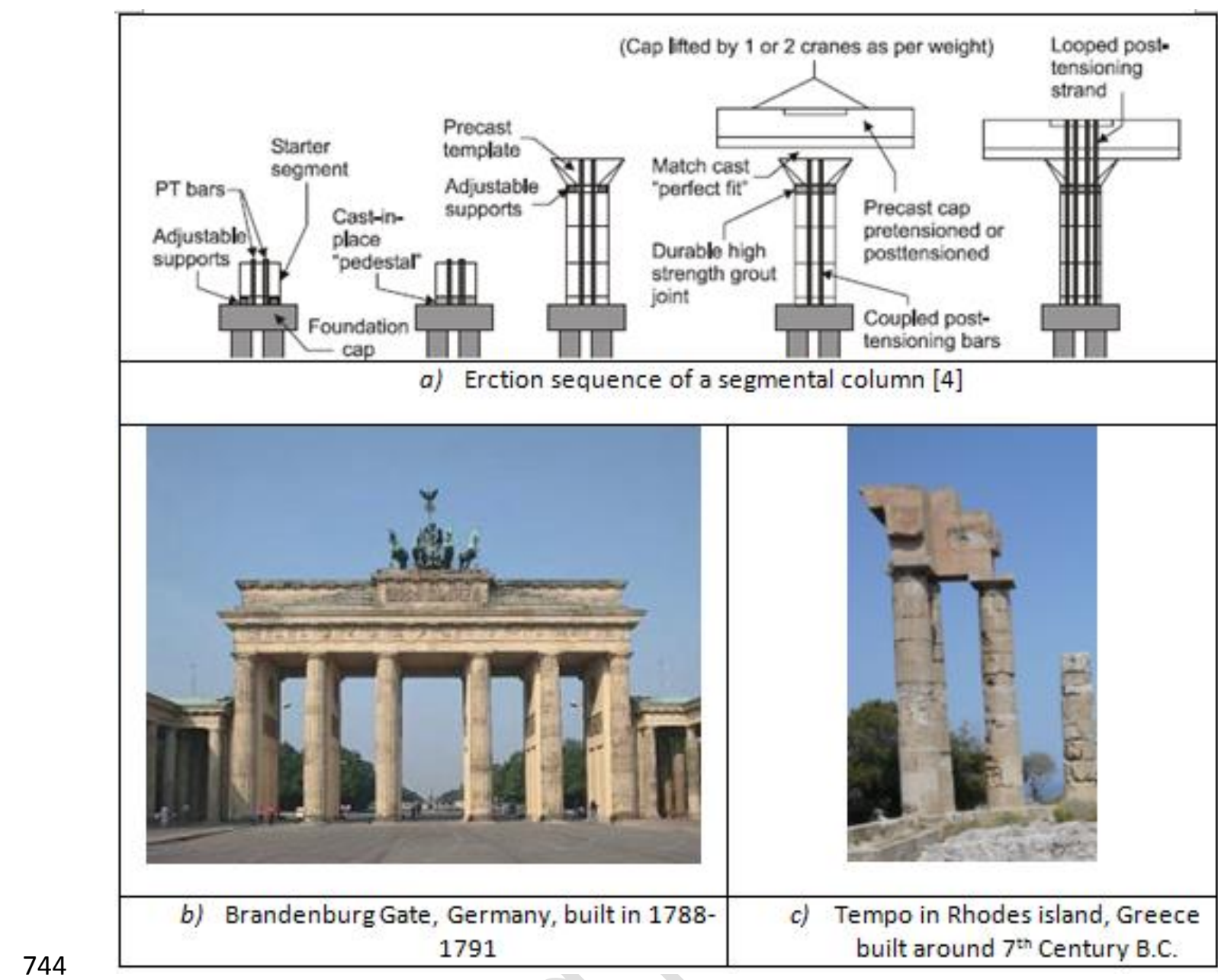

Figure 1 Ancient and modern constructions of segmental columns 


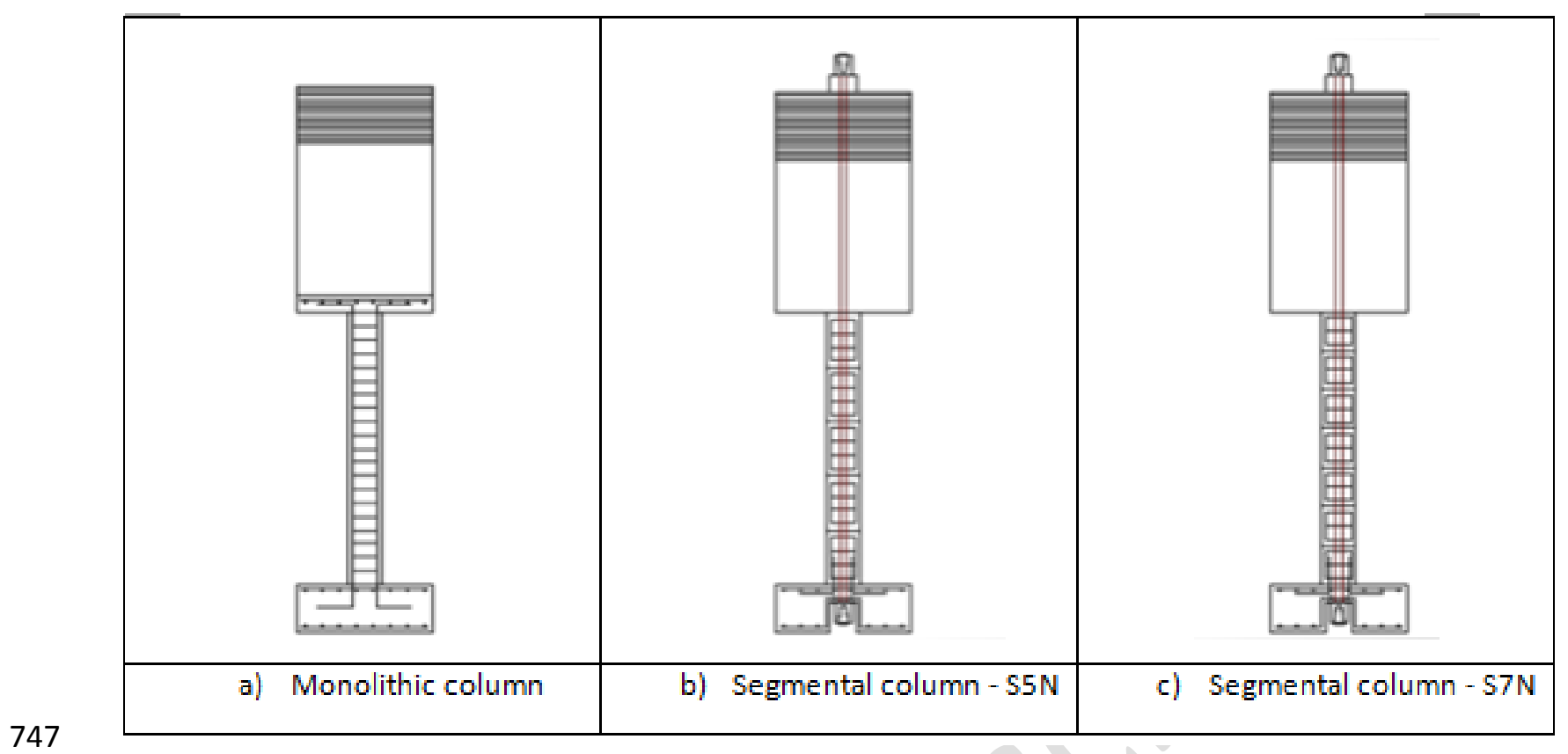




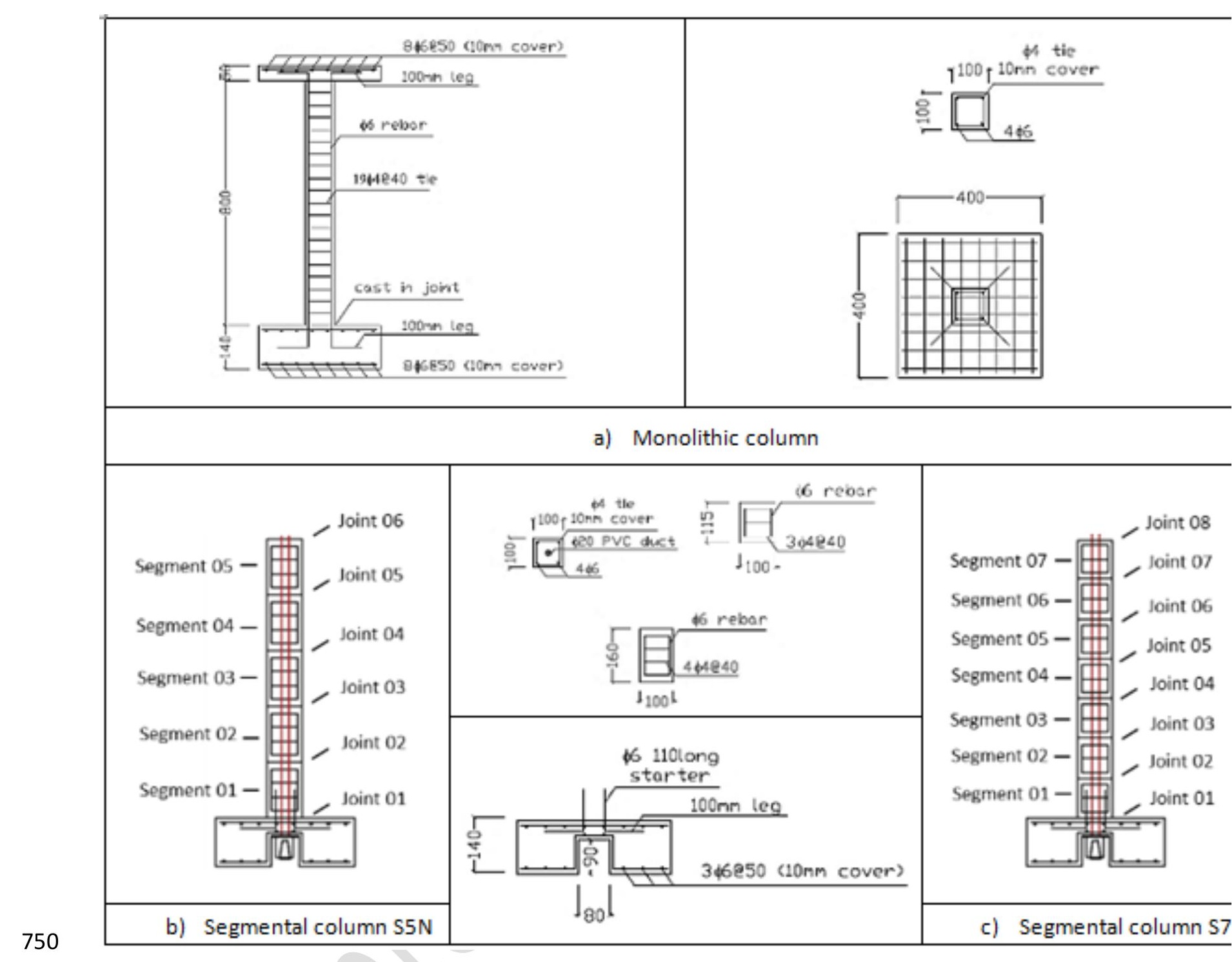




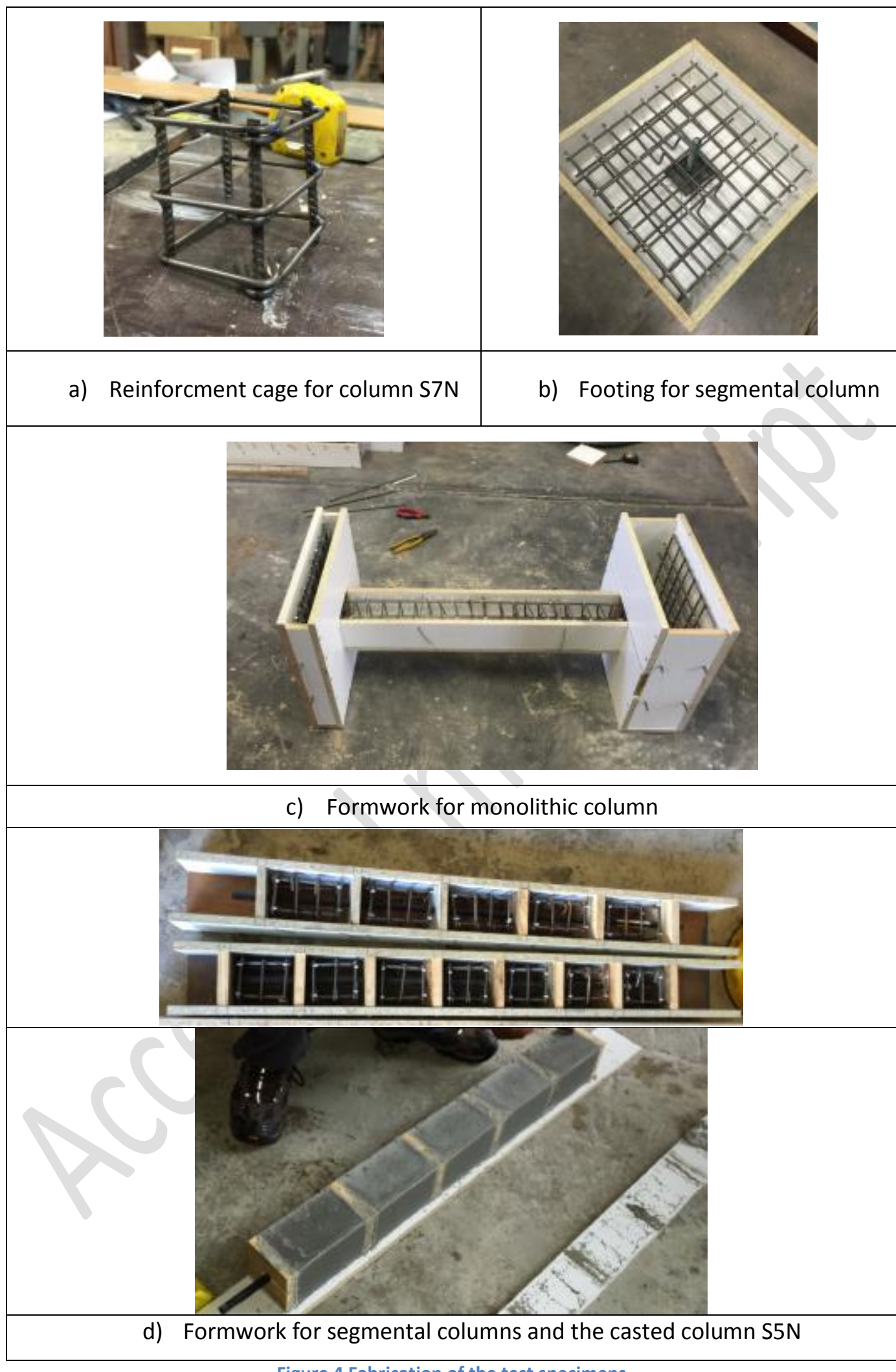




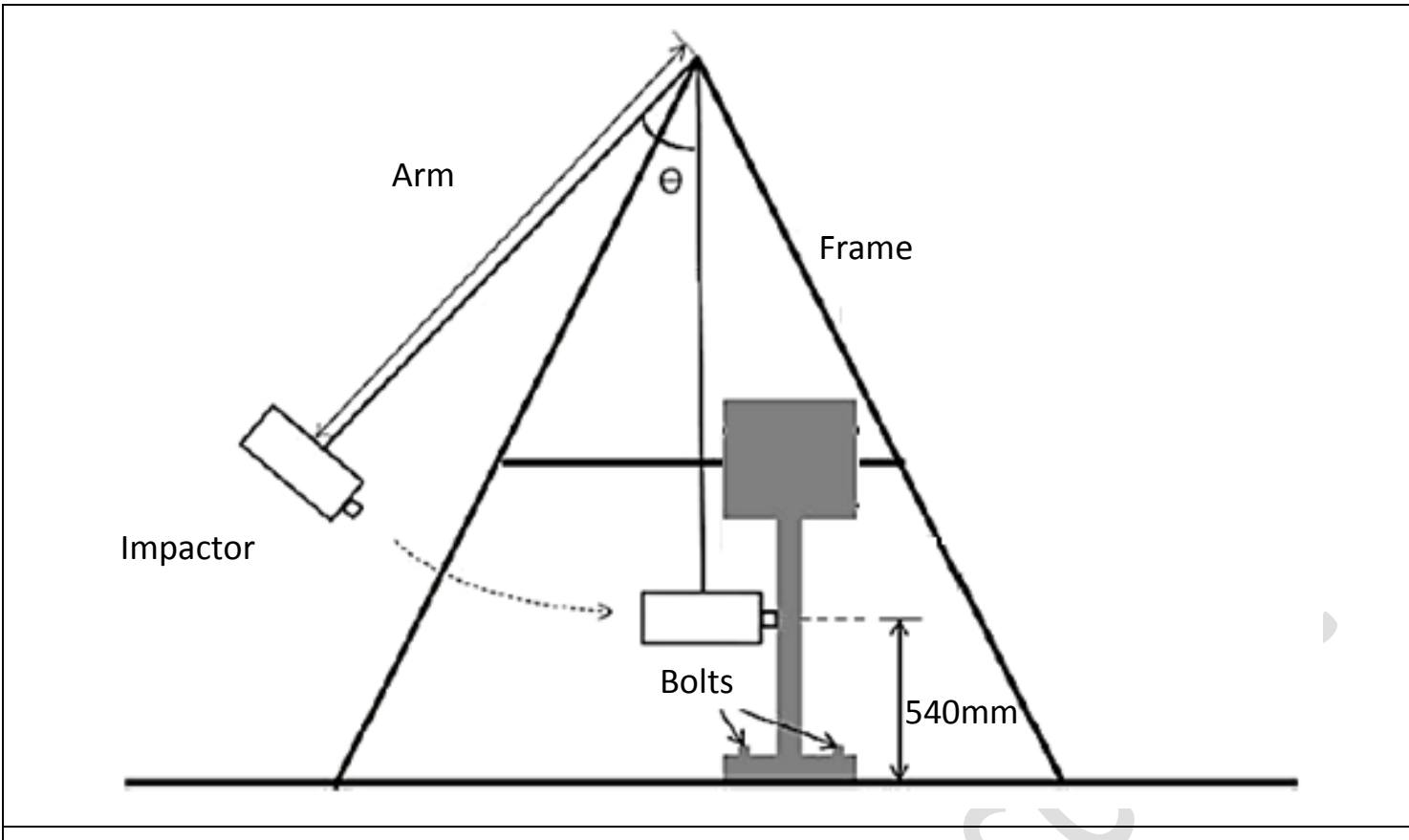

a) Schematic view of pendulum impact system
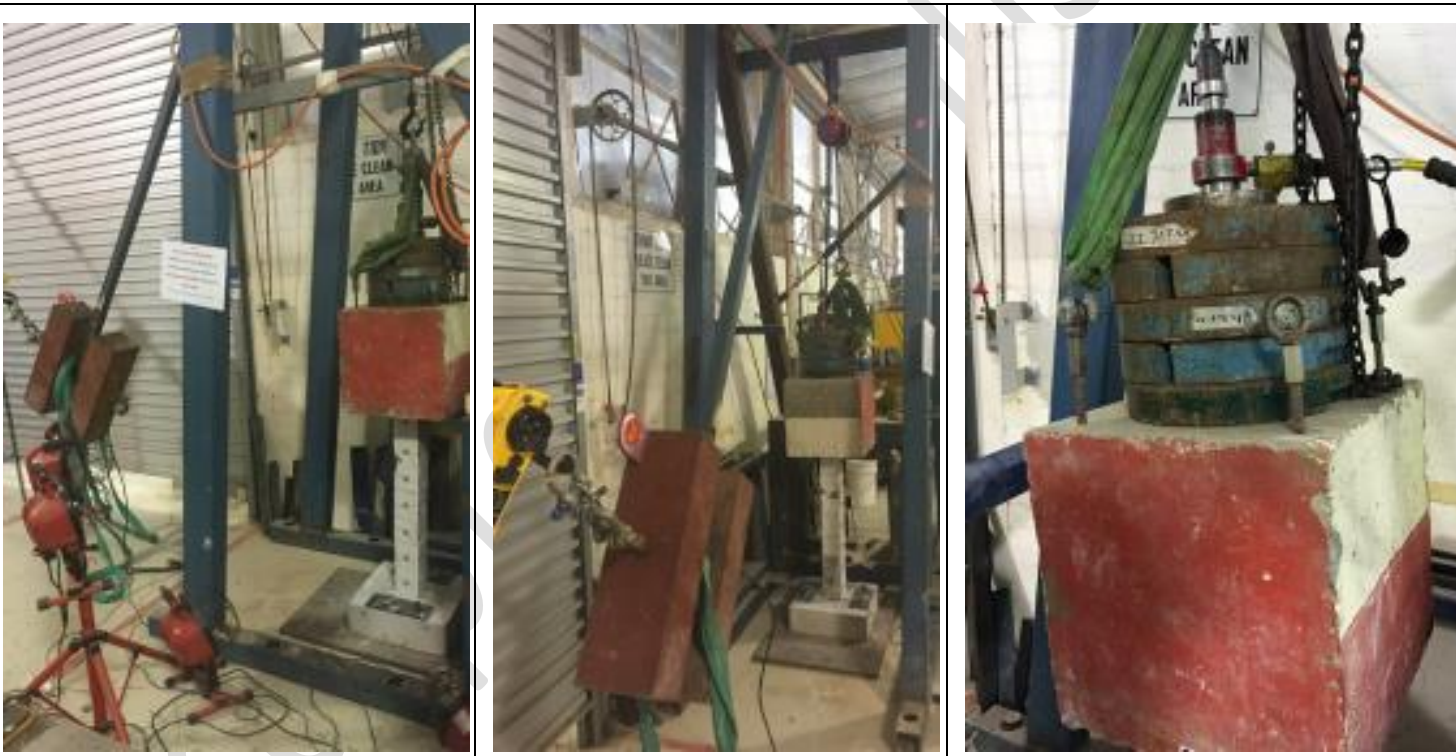

b) The ready-to-go impact system and setup details 


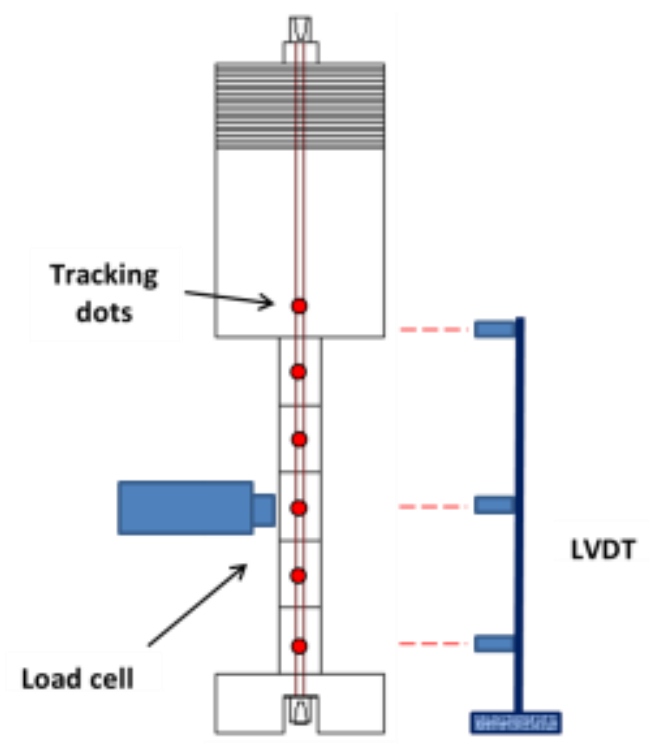

HS

camera

Figure 6 Measurement system for the pendulum impact test

759 


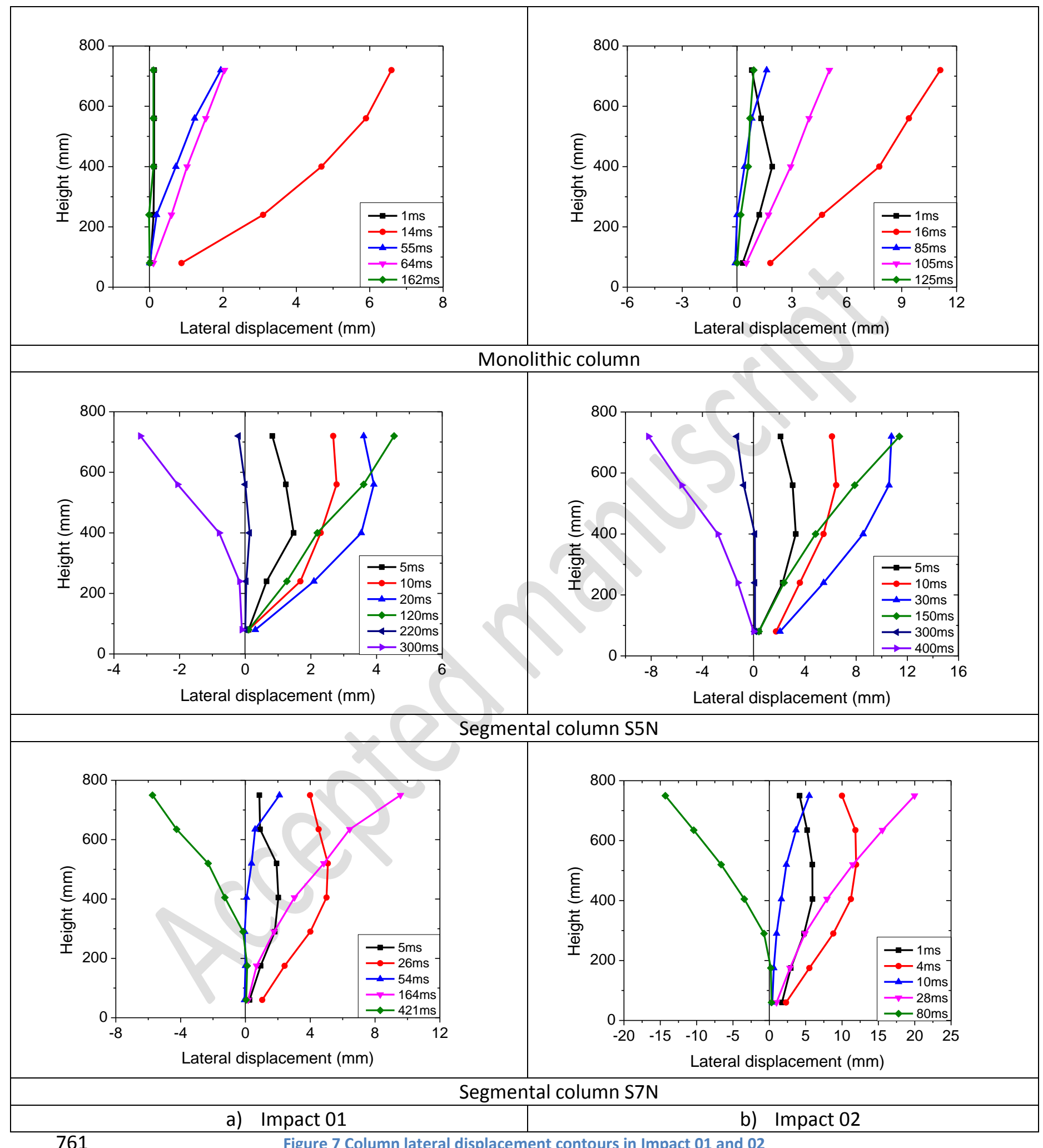









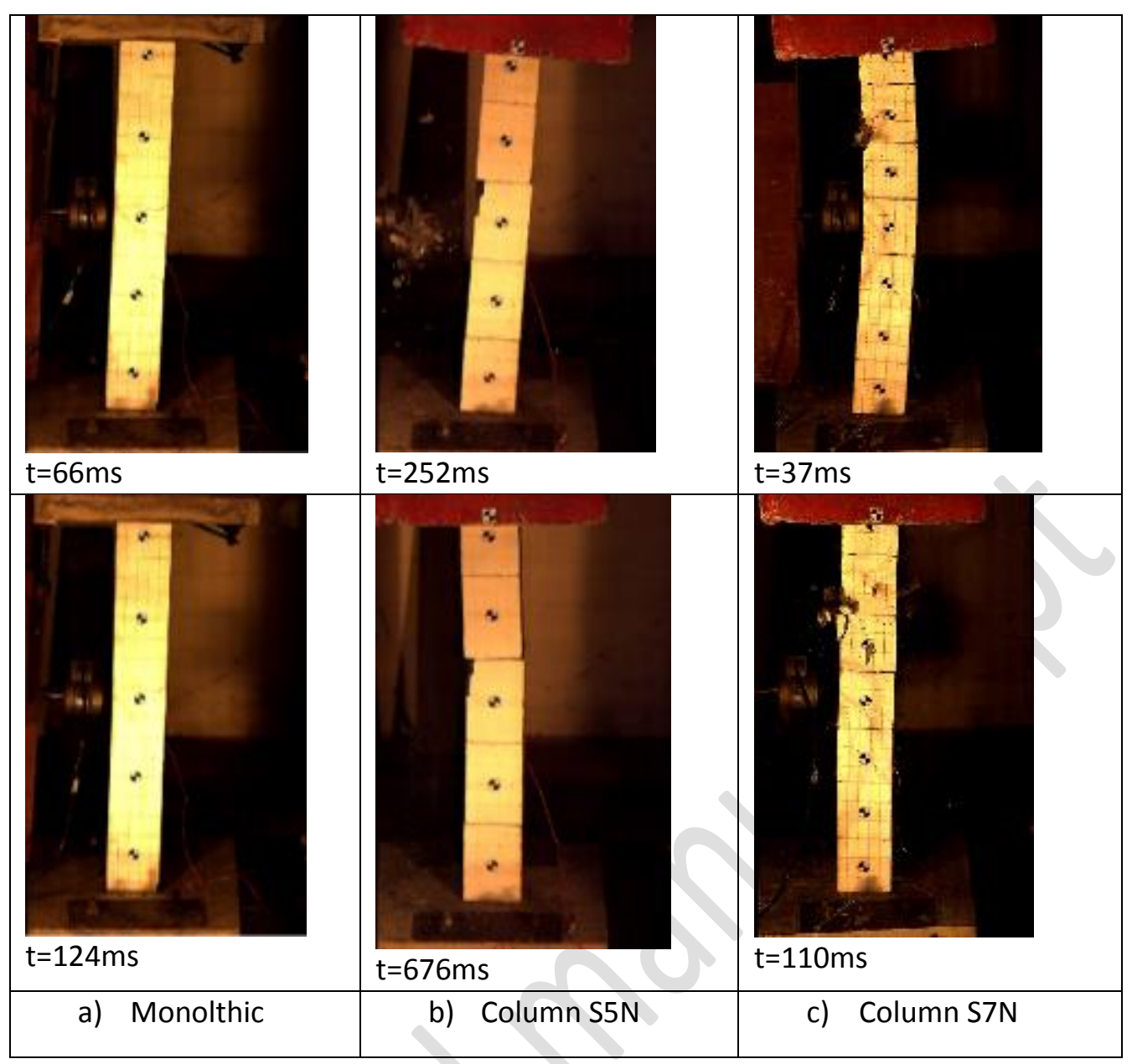

763

Figure 8 High-speed camera images of columns in Impact 03 


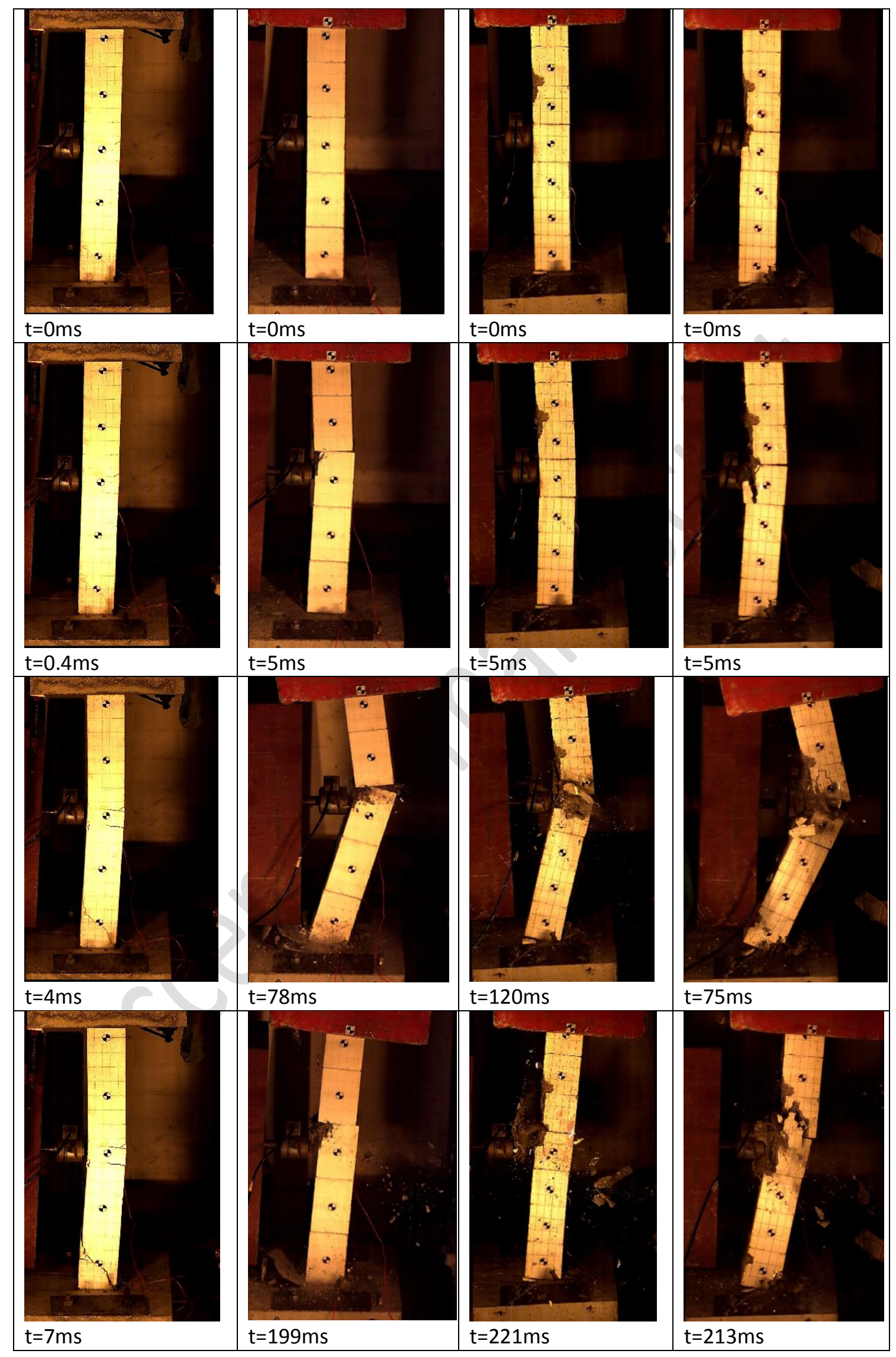




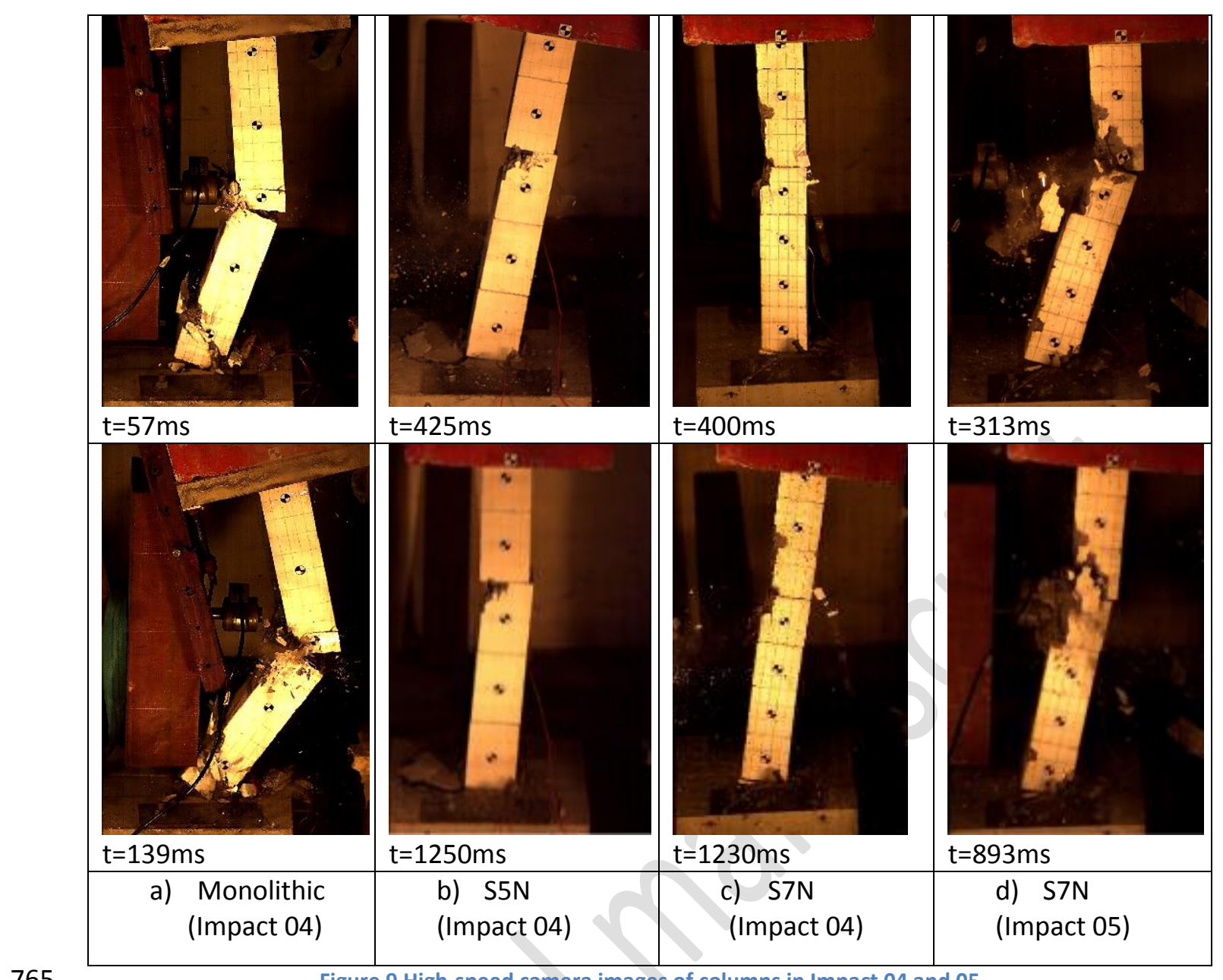

765

Figure 9 High-speed camera images of columns in Impact 04 and 05

766 


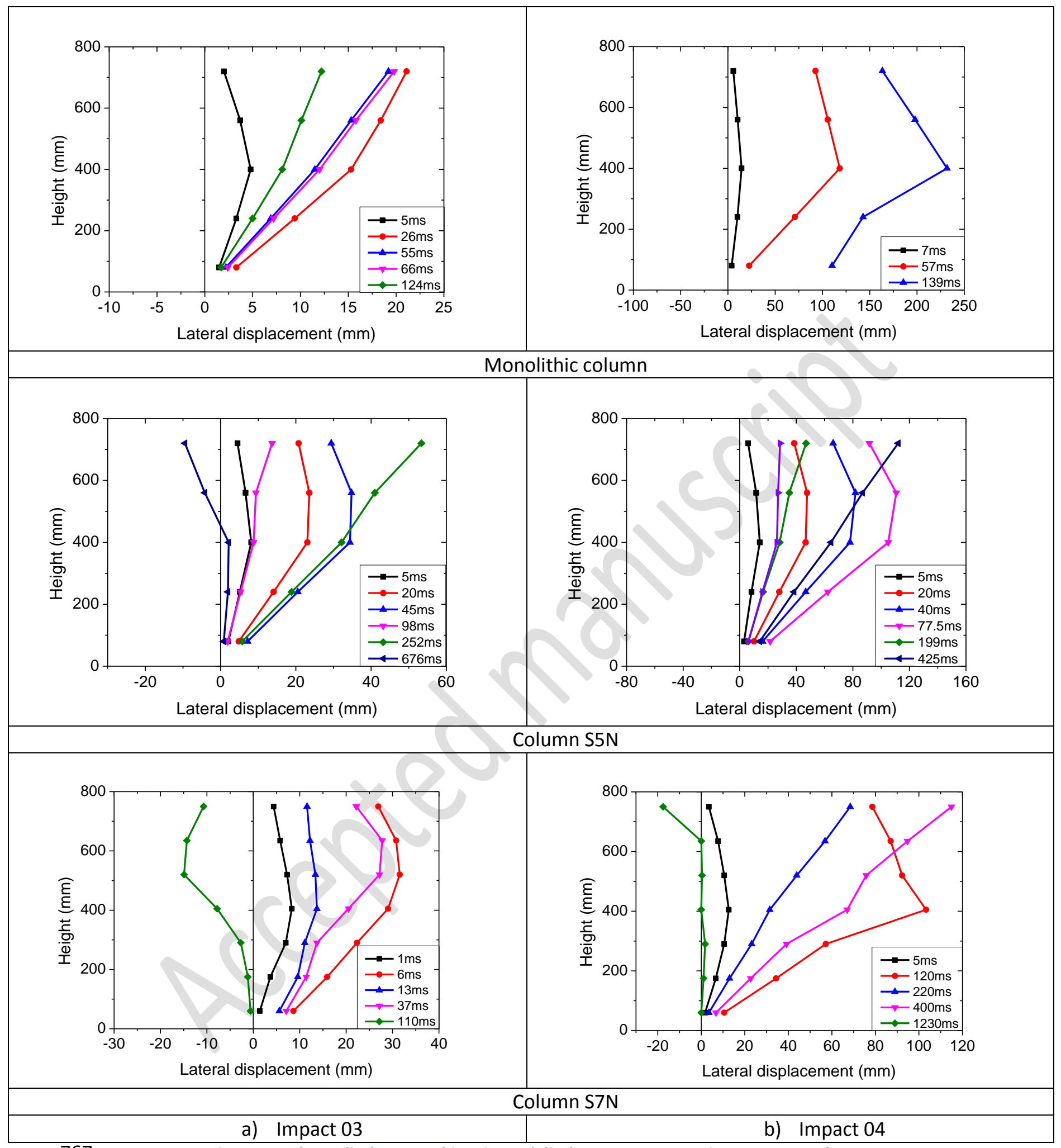

767

Figure 10 Column displacement histories and displacement contours in Impact 03 and 04 


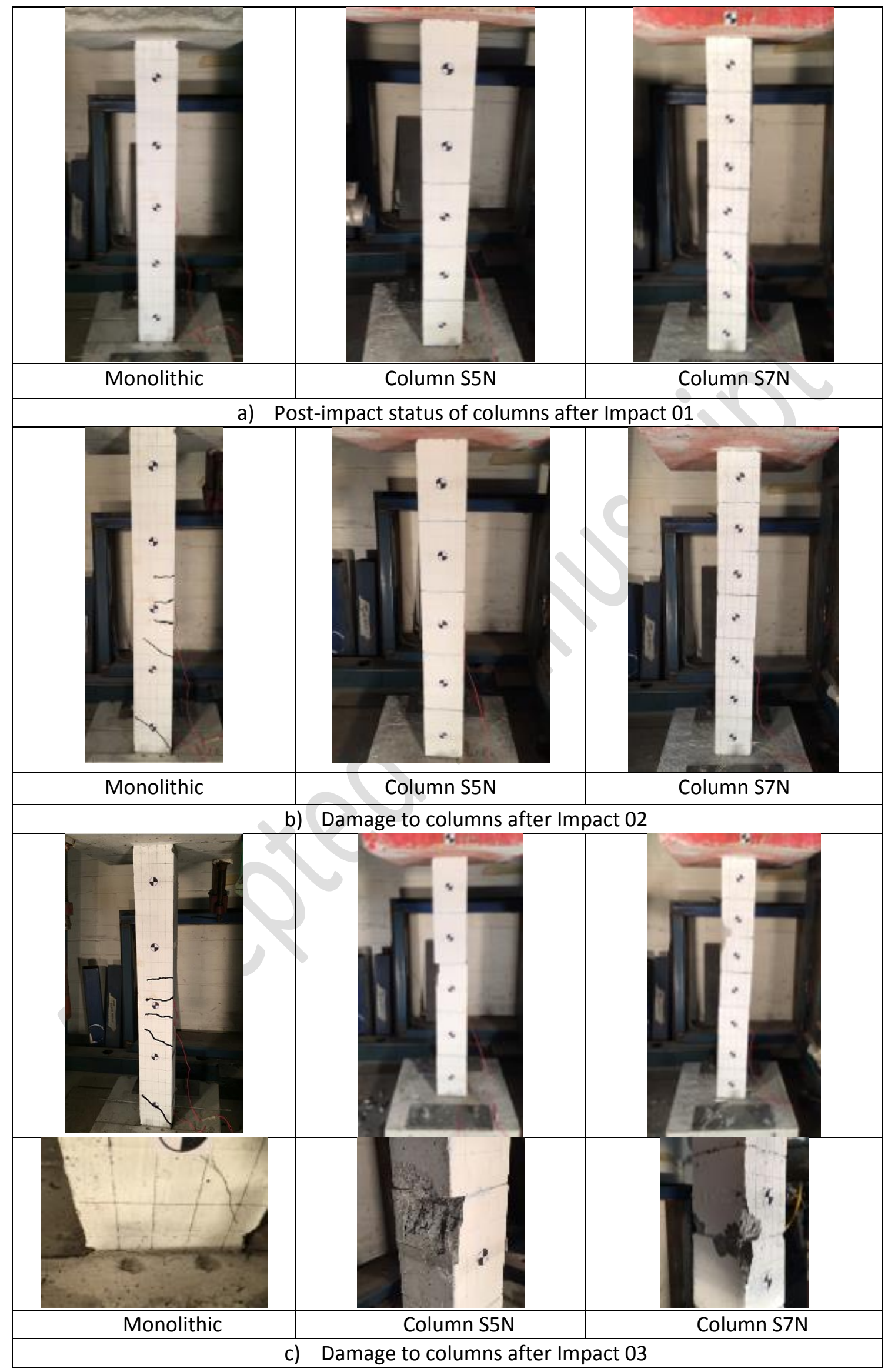




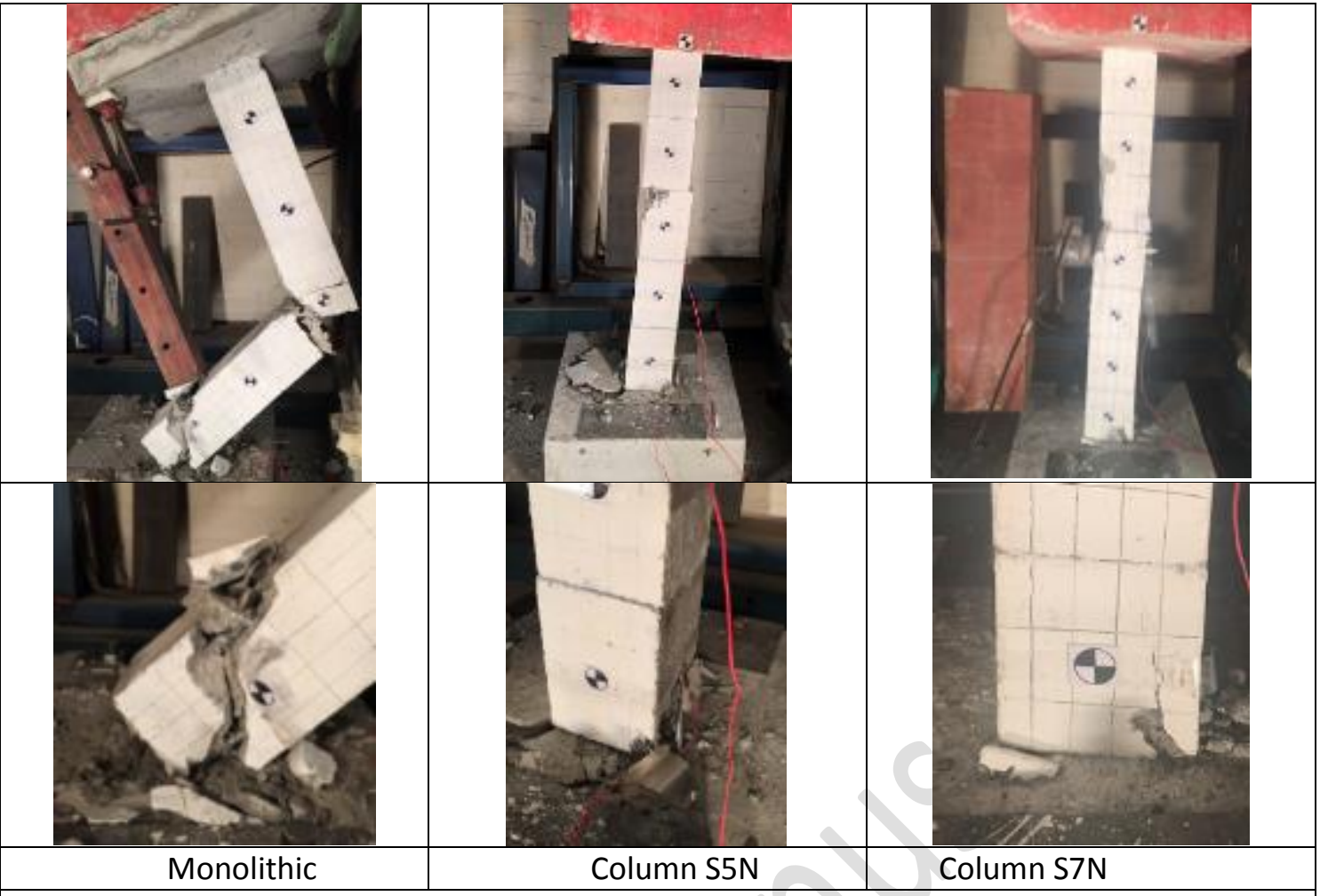

d) Damage to columns after Impact 04

Damage to column S7N after Impact 05

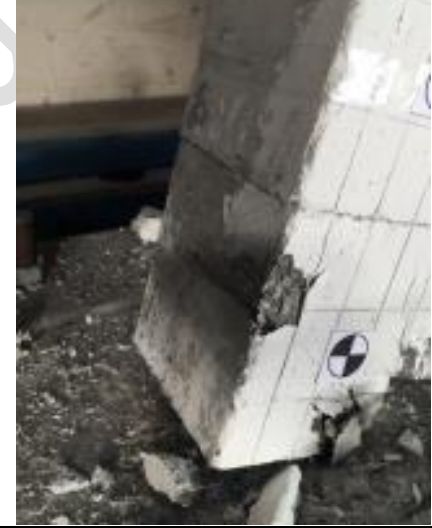

Figure 11 Post-impact status of columns 


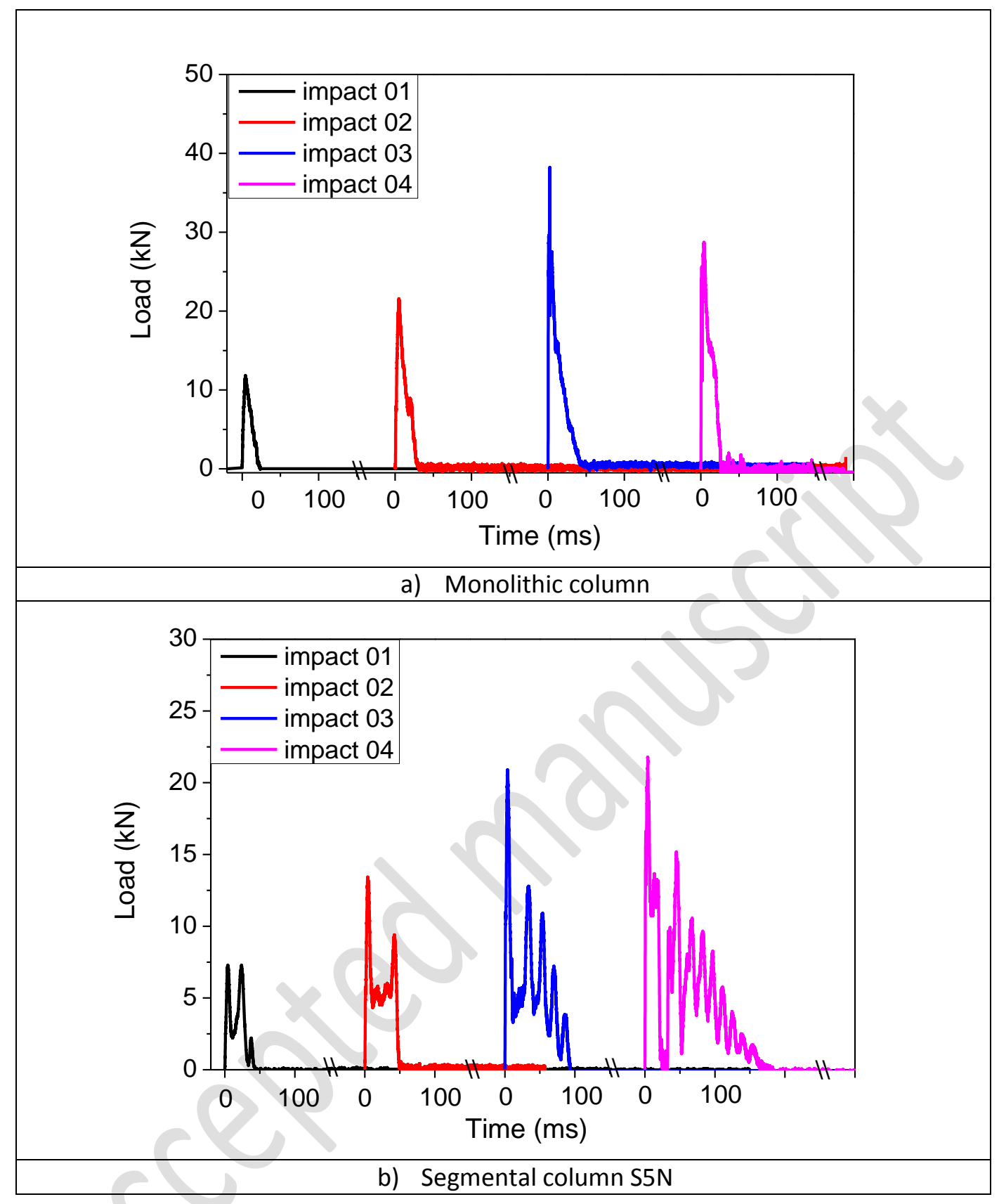




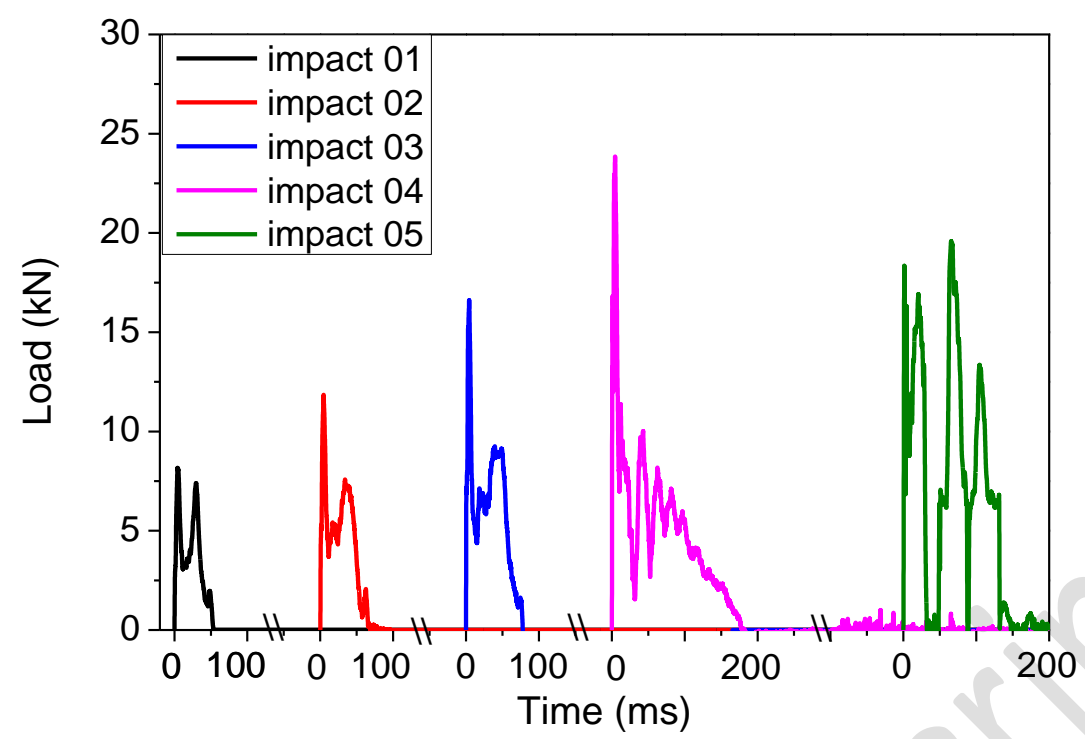

c) Segmental column S7N

771

Figure 12 Load time histories

772 


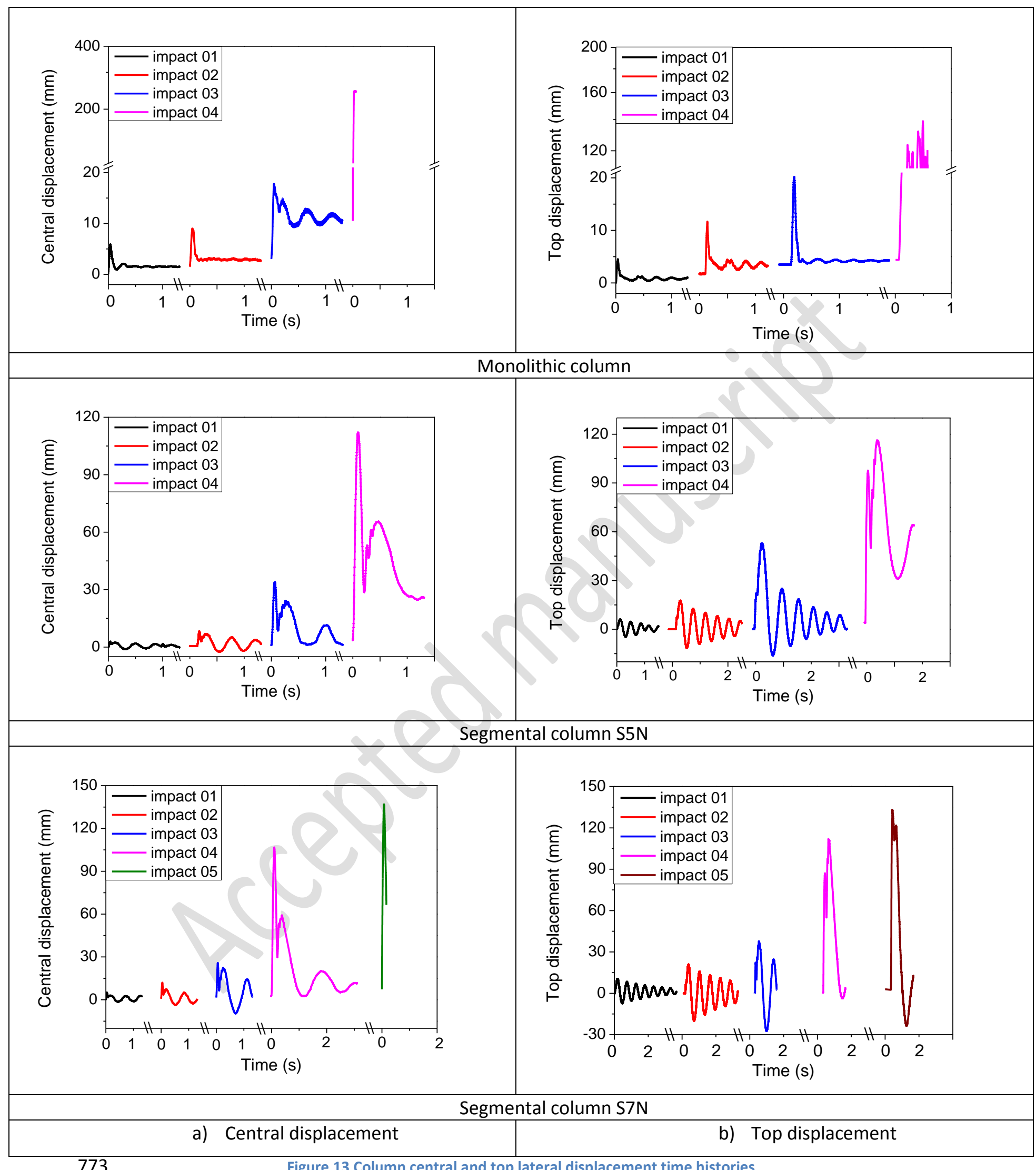




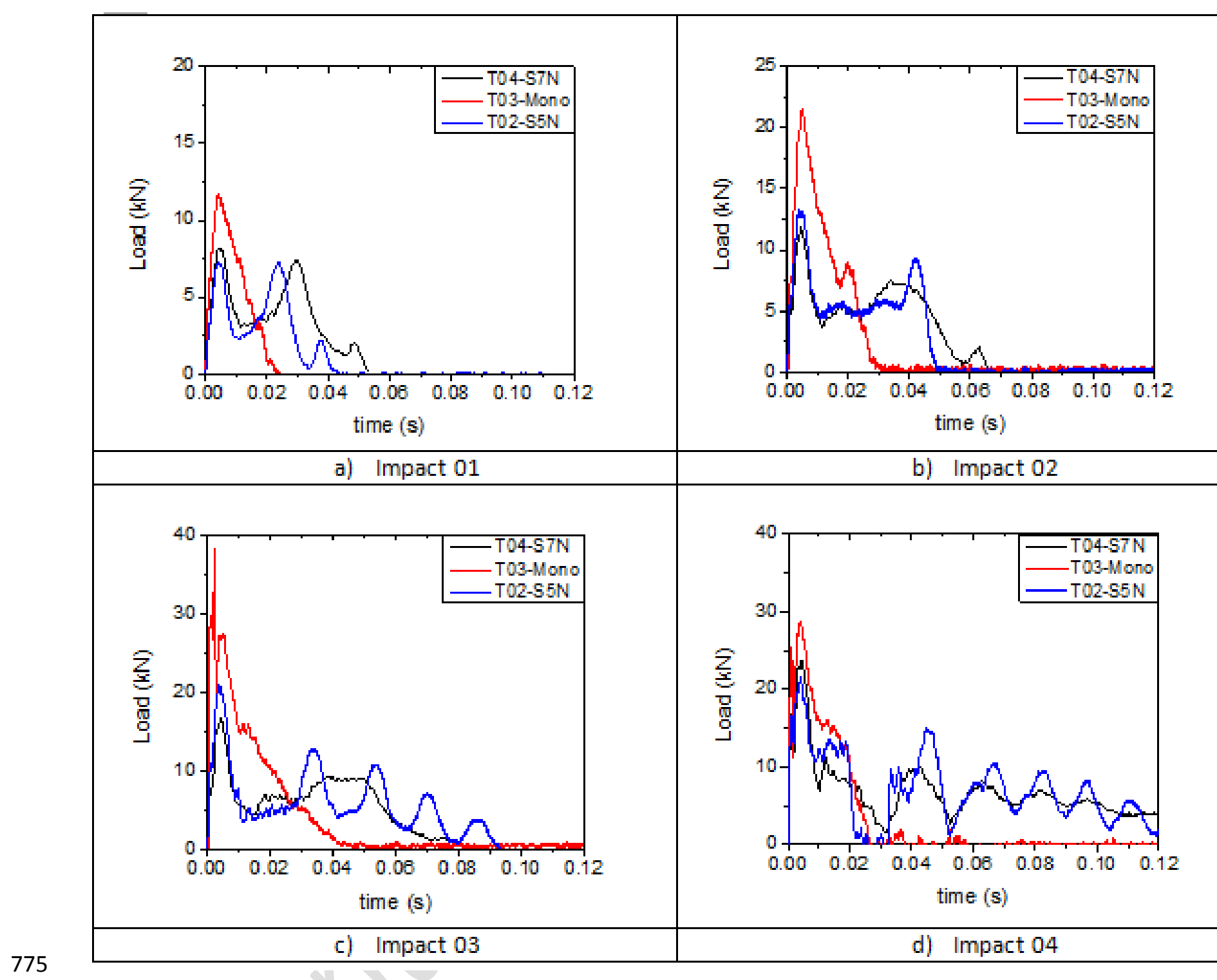




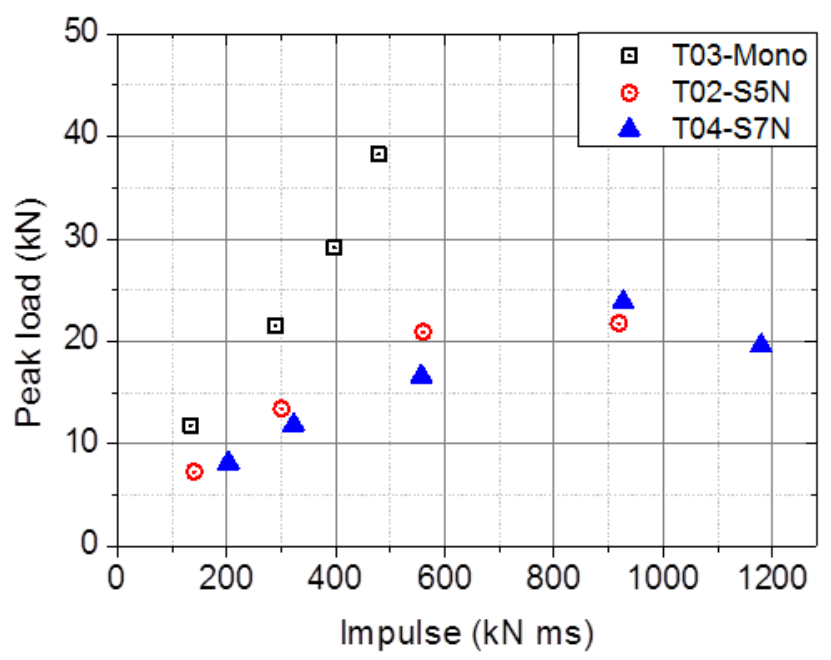

779

Figure 15 Peak impact loads vs. impulses 


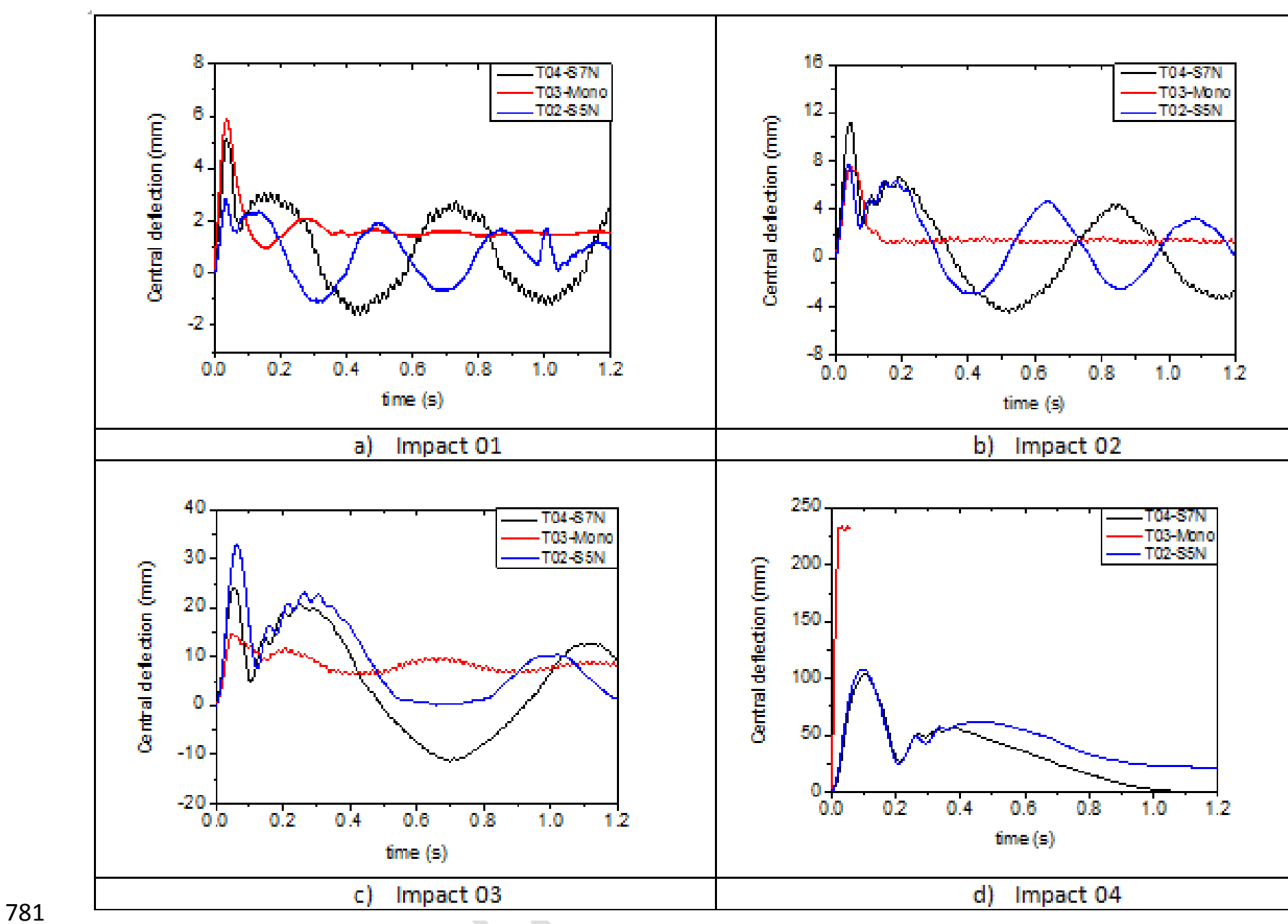

Figure 16 Comparison of column central deflection time histories 

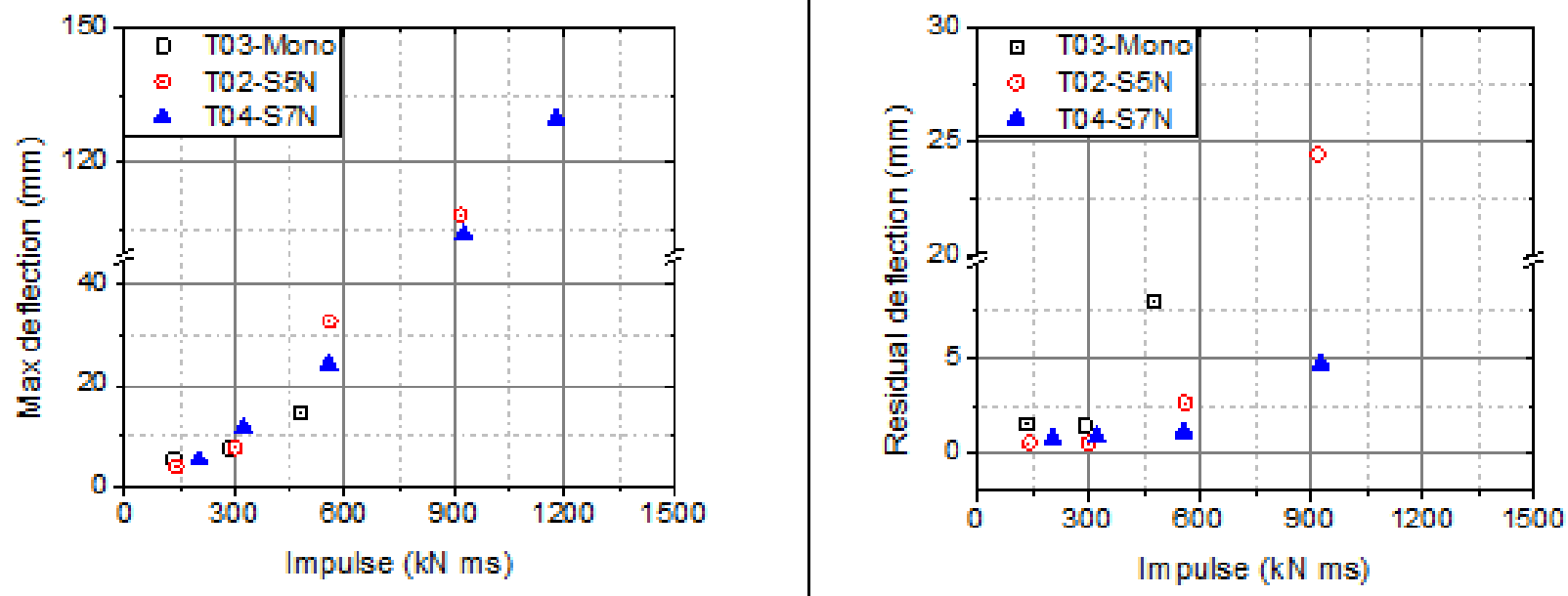


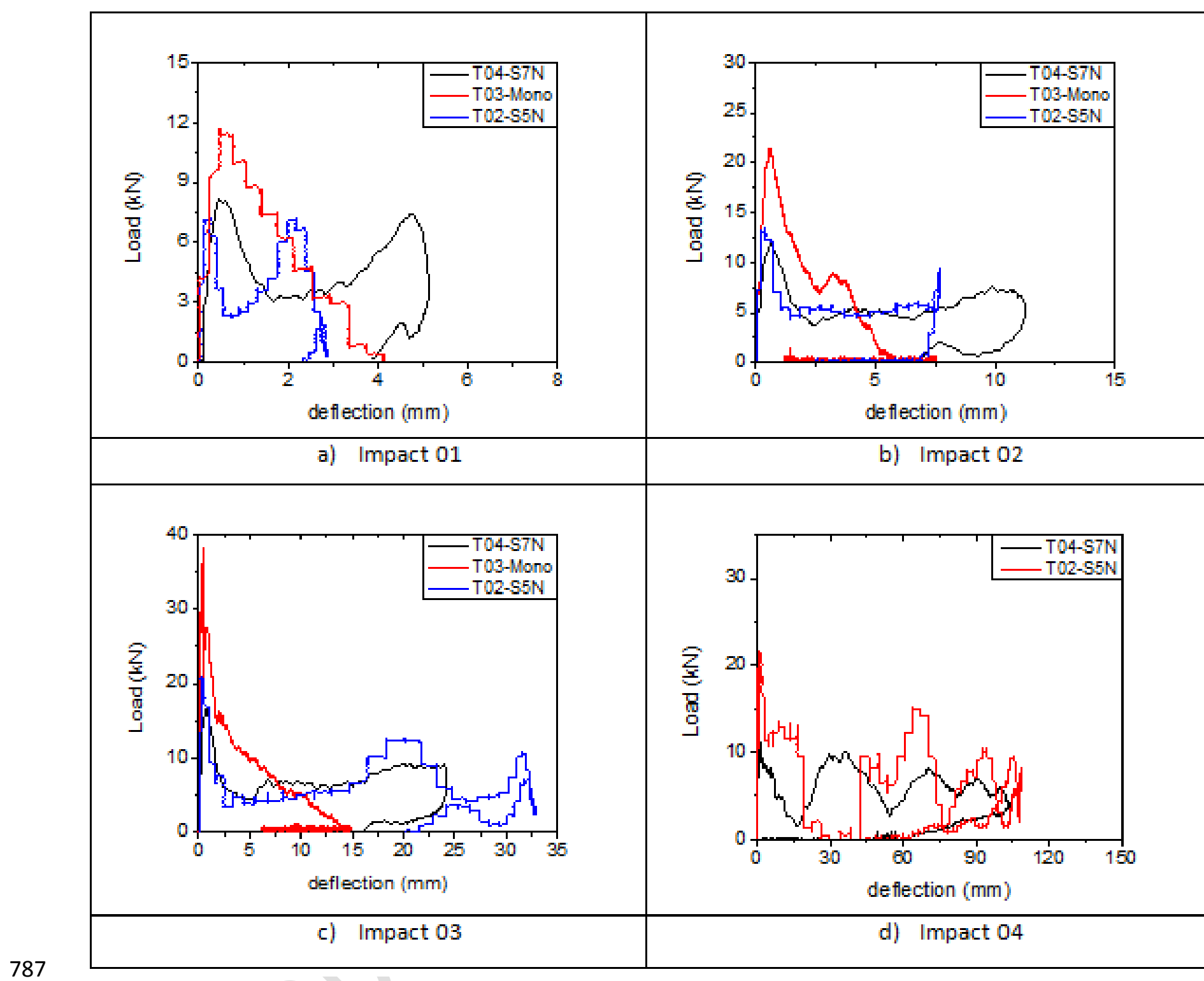




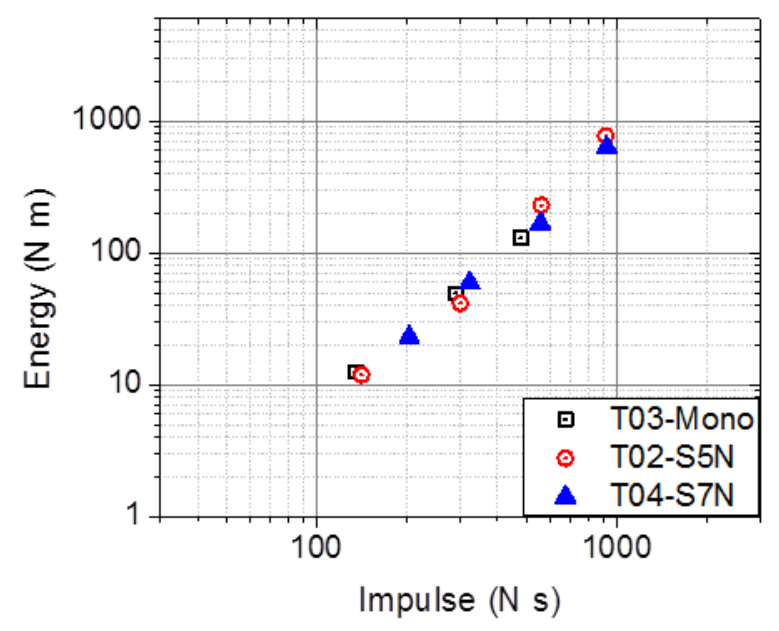

790

Figure 19 Energy dissipation vs impulse

791

792 


\begin{tabular}{cccccc}
\hline Column & $\begin{array}{c}\text { Height } \\
(\mathrm{mm})\end{array}$ & $\begin{array}{c}\text { Cross-section } \\
\text { dimension } \\
(\mathrm{mm} \times \mathrm{mm})\end{array}$ & $\begin{array}{c}\phi_{\text {long, rebar }}{ }^{*} \\
(\mathrm{~mm})\end{array}$ & $\begin{array}{c}\phi_{\text {tie }}{ }^{*} \\
(\mathrm{~mm})\end{array}$ & $\begin{array}{c}\text { Longitudinal } \\
\text { reinforcement } \\
\text { ratio (\%) }\end{array}$ \\
\hline Monolithic & 800 & $100 \times 100$ & 6 & 4 & 1.14 \\
S5N & 800 & $100 \times 100$ & 6 & 4 & 1.16 \\
S7N & 800 & $100 \times 100$ & 6 & 4 & 1.16 \\
\hline
\end{tabular}

Table 1 Specifications of the test specimens

795 


\begin{tabular}{ccccc}
\hline Material & $\begin{array}{c}\rho \\
(\mathrm{kg} / \mathrm{m} 3)\end{array}$ & $\begin{array}{c}\mathrm{fc}^{\prime} \\
(\mathrm{MPa})\end{array}$ & $\begin{array}{c}\mathrm{f}_{\mathrm{t}}, \mathrm{f}_{\mathrm{y}}\left(\text { or } \mathrm{f}_{\text {proof }}\right) \\
(\mathrm{MPa})\end{array}$ & $\begin{array}{c}\mathrm{E} \\
(\mathrm{GPa})\end{array}$ \\
\hline Concrete & 2400 & 34 & 5 & 30 \\
Longitudinal rebar & 7800 & - & 500 & 200 \\
Tie & 7800 & - & 300 & 200 \\
Prestress tendon & 7850 & - & 1860 & 195 \\
\hline \multicolumn{4}{r}{} & Table 2 Material properties
\end{tabular}

797 


\begin{tabular}{|c|c|c|c|c|c|c|c|c|c|c|}
\hline \multirow[b]{2}{*}{ Specimen } & \multicolumn{2}{|c|}{ Impact 01} & \multicolumn{2}{|c|}{ Impact 02} & \multicolumn{2}{|c|}{ Impact 03} & \multicolumn{2}{|c|}{ Impact 04} & \multicolumn{2}{|c|}{ Impact 05} \\
\hline & $\begin{array}{l}F_{\text {peak }} \\
(\mathrm{kN})\end{array}$ & $\begin{array}{c}\mathrm{I} \\
(\mathrm{kN} \mathrm{ms})\end{array}$ & $\begin{array}{l}\mathrm{F}_{\text {peak }} \\
(\mathrm{kN})\end{array}$ & $\begin{array}{c}\mathrm{I} \\
(\mathrm{kN} \mathrm{ms})\end{array}$ & $\begin{array}{l}F_{\text {peak }} \\
(k N)\end{array}$ & $\begin{array}{c}\mathrm{I} \\
(\mathrm{kN} \mathrm{ms})\end{array}$ & $\begin{array}{l}\mathrm{F}_{\text {peak }} \\
(\mathrm{kN})\end{array}$ & $\begin{array}{c}\mathrm{I} \\
(\mathrm{kN} \mathrm{ms})\end{array}$ & $\begin{array}{l}\mathrm{F}_{\text {peak }} \\
(\mathrm{kN})\end{array}$ & $\begin{array}{c}\mathrm{I} \\
(\mathrm{kN} \mathrm{ms})\end{array}$ \\
\hline Monolithic & 11.81 & 134 & 21.58 & 290 & 38.22 & 478 & 29.12 & 397 & - & - \\
\hline S5N & 7.29 & 141 & 13.44 & 301 & 20.91 & 560 & 21.78 & 918 & - & - \\
\hline S7N & 8.17 & 203 & 11.85 & 323 & 16.61 & 557 & 23.85 & 926 & 19.59 & 1179 \\
\hline
\end{tabular}

799 
a) Column central maximum and residual displacements

\begin{tabular}{|c|c|c|c|c|c|c|c|c|}
\hline \multirow[b]{2}{*}{ Specimen } & \multicolumn{2}{|c|}{ Impact 01} & \multicolumn{2}{|c|}{ Impact 02} & \multicolumn{2}{|c|}{ Impact 03} & \multicolumn{2}{|c|}{ Impact 04} \\
\hline & $\begin{array}{c}\delta_{\max } \\
(\mathrm{mm})\end{array}$ & $\begin{array}{c}\delta_{\text {resi. }} \\
(\mathrm{mm})\end{array}$ & $\begin{array}{c}\delta_{\max } \\
(\mathrm{mm})\end{array}$ & $\begin{array}{c}\delta_{\text {resi. }} \\
(\mathrm{mm})\end{array}$ & $\begin{array}{c}\delta_{\text {resi. }} \\
(\mathrm{mm})\end{array}$ & $\begin{array}{c}\delta_{\max } \\
(\mathrm{mm})\end{array}$ & $\begin{array}{c}\delta_{\max } \\
(\mathrm{mm})\end{array}$ & $\begin{array}{c}\delta_{\text {resi. }} \\
(\mathrm{mm})\end{array}$ \\
\hline Monolithic & 5.2 & 1.5 & 7.5 & 2.9 & 14.6 & 11.0 & - & - \\
\hline S5N & 3.0 & 0.5 & 7.7 & 1.0 & 32.8 & 3.6 & 108.4 & 28.0 \\
\hline S7N & 5.1 & 0.7 & 11.5 & 1.6 & 24.3 & 2.6 & 104.2 & 7.3 \\
\hline
\end{tabular}

801

$* \delta$ represents lateral displacement

802

b) Column top maximum and residual displacements

\begin{tabular}{|c|c|c|c|c|c|c|c|c|}
\hline \multirow[b]{2}{*}{ Specimen } & \multicolumn{2}{|c|}{ Impact 01} & \multicolumn{2}{|c|}{ Impact 02} & \multicolumn{2}{|c|}{ Impact 03} & \multicolumn{2}{|c|}{ Impact 04} \\
\hline & $\begin{array}{c}\delta_{\max } \\
(\mathrm{mm})\end{array}$ & $\begin{array}{c}\delta_{\text {resi. }} \\
(\mathrm{mm})\end{array}$ & $\begin{array}{c}\delta_{\max } \\
(\mathrm{mm})\end{array}$ & $\begin{array}{c}\delta_{\text {resi. }} \\
(\mathrm{mm})\end{array}$ & $\begin{array}{c}\delta_{\max } \\
(\mathrm{mm})\end{array}$ & $\begin{array}{c}\delta_{\text {resi. }} \\
(\mathrm{mm})\end{array}$ & $\begin{array}{c}\delta_{\max } \\
(\mathrm{mm})\end{array}$ & $\begin{array}{c}\delta_{\text {resi. }} \\
(\mathrm{mm})\end{array}$ \\
\hline Monolithic & 6.6 & 1.9 & 11.7 & 3.7 & 21.1 & 4.3 & & - \\
\hline S5N & 6.1 & 0.7 & 17.6 & 1.8 & 52.9 & 3.8 & 116.3 & 41.8 \\
\hline S7N & 10.6 & 0.7 & 21.0 & 2.4 & 37.6 & 4.4 & 111.9 & 6.9 \\
\hline
\end{tabular}

803

* $\delta$ represents lateral displacement

804

Table 4 Summary of maximum and residual displacements

805 
